
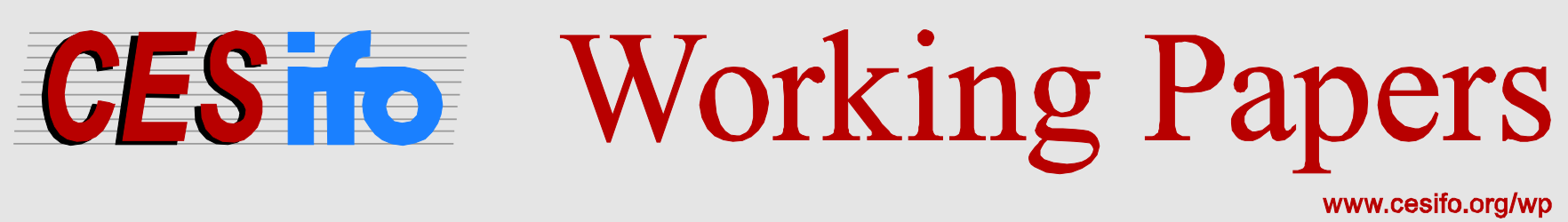

\title{
Strategic Currency Choice in International Trade
}

\author{
Maria V. Sokolova \\ CESIFO WORKING PAPER NO. 5574 \\ CATEgORY 7: MONETARY POLICY AND INTERNATIONAL FINANCE \\ OCTOBER 2015
}

An electronic version of the paper may be downloaded

- from the SSRN website:

- from the RePEc website:

- from the CESifo website:

www.SSRN.com

www.RePEc.org

www.CESifo-group.org/wp 


\title{
Strategic Currency Choice in International Trade
}

\begin{abstract}
How exporters choose currency for their exports? Using highly disaggregated data on the population of Russian Federation exporting firms between 2005 and 2009 this paper studies the strategic determinants of currency invoicing decisions. Strategic morives embrace two occurrences in currency choice: firstly, the realisation of bargaining powers of the seller and the buyer, where I perform a novel firm-level test. Notably, in contrast to the micro and macro determinants, bargaining powers are found to have different effect on currency choice at the aggregate and firm level. On the industry level, higher bargaining power of the participating countries lessens the reliance on "vehicle" currency and increases the probability of use of the trading partners' currencies, whereas the increase of the firm level bargaining power increases the probability of application of the vehicle currency. This indicates that the firm-level dimension should be taken into account when making inferences on currency denomination. Secondly, strategic currency choice determinants include competition-enhanced characteristics of international trade: the novel evidence suggests the firm-level currency choice "mimicking" between the firms and the preference of vehicle currency for the relatively cheaper goods. The robustness of these results is tested among the subsamples of heterogeneous exporters sizes and I find that the expansion of the bilateral trading partners' currencies usage is mostly sourced from the smaller exporters. On the whole, the results of this paper support the "bargaining over invoicing” theory, which indicates that increases in firms' export size change the buyer's and seller's preferences over currency invoicing.
\end{abstract}

JEL-Codes: F100, F400, C330.

Keywords: currency pricing, strategic choice, pass-through, transaction data, export data, vehicle currency, emerging economy.

\author{
Maria V. Sokolova \\ The Graduate Institute of International and \\ Development Studies / Department of International Economics \\ Chemin Eugene-Rigot, 2 \\ Switzerland - 1202 Geneve \\ maria.sokolova@graduateinstitute.ch
}

October 12, 2015

First version: December 2013

I am grateful to Cedric Tille, Damien Neven, Nicolas Berman and to GEP CEPR Postgraduate Conference in Nottingham, especially Wanyu Chung, seminar participants at the Graduate Institute of Geneva, Young Swiss Economists Meeting 2014 (at the University of Bern) of the Swiss Economic Society, Ruhr Doctoral Conference and Scottish Economic Society, European Economic Association. Special thanks to Natalya Volchkova (New Economics School, Moscow). Financial support of the Graduate Institute of Geneva and Swiss National Science Foundation is gratefully acknowledged. 


\section{Introduction}

The recent expansion of the world trade has positioned many questions in a new scope. The questions on how exporters decide on the currency for their activity, which motives lead them to their preferences and how it affects their activity, has been granted an increasing attention of many scholars and policy-makers. The currency choice channels the uncertainties faced by the producer and the customer, determining who and to what extent gets exposed to the exchange rate risk. Using a unique dataset this paper looks at the relatively novel dimension of this question - what role the strategic currency choice determinants play in determining these choices. This paper defines the strategic currency choice determinants as those resulting from either competition or bargaining side of international trade. The former has been discussed earlier in the literature as the relevance of market structure for the optimal currency choice (Bacchetta \& van Wincoop, 2005 ; Auer \& Schoenle, 2012; Goldberg \& Tille, 2008a b; Devereux et al. , 2015), whereas the relevance of the bargaining motives for the currency choice is a new concept (Goldberg \& Tille, n.d.) and has yet to be explored.

The bargaining theory of currency invoicing ${ }^{1}$ concerns with the fact that every international trade transaction is a result of a contract which is being negotiated over three dimensions - price, quantity and currency. Among the three possibilities of currency pricing: PCP - "producer currency pricing", LCP - "local currency pricing" and VCP "vehicle currency pricing" - the first two are bound to the economies of the seller and the buyer respectively, whereas the third one represents the choice of a currency of a country that is not participating in the exporting contract. The most popular VCP currency is USD, while the discussion of the reasons of the use of USD in international trade goes back to Bretton Woods system, the consequences of the hegemony of the USD in international trade came much later when the data became available ${ }^{2}$. The application of the unique dataset of the transaction-track decisions of the currency choices of the Russian exporters allows us to shed light on the role of the strategic motives in currency choice in the domination of the VCP pricing (and therefore, USD) in international trade.

By utilising the most recent research on currency invoicing Bacchetta \& van Wincoop (2005); Goldberg \& Tille (2008a b, n.d.) I build up a test of the currency pricing determinants of Russian exporters; at the main concern of this paper the role of strategic determinants in decision between using the currencies of the trading partners and the vehicle currency is put. In the scarce number of papers that have empirical tests of currency choice determinants, usually PCP is used as the base category, as it is, subject to controls, default preference of domestic supplier as it has to pay the wage bill in domestic currency. The difference of this paper to all available empirical papers on currency choice up to date, to my knowledge, is that it utilizes the data of a country with relatively not so strong currency, which is rarely used as a reserve and store of value outside its own borders, and used as means of payment only in trade and investment between itself and

\footnotetext{
${ }^{1}$ Terms "currency pricing" and "currency invoicing" are used interchangeably, as for overhwhelming majority of the exporters, as documented in the example of Sweden (Friberg \& Wilander, 2008) the currency of the contract, the currency of invoice and the currency of settlement - therefore the actual currency recieved - is the same.

2 Grassman (1973, 1976) was the first one to document the data on currencies used in international trade, but the data limitations drove the result of the conclusion that the advanced countries use the currency of the exporter. The later works Friberg (1998); Fry \& Harris $(1996)$ and the country cases Friberg \& Wilander (2008); Ito et al. (2010) have all challenged this conclusion by finding much more intricate conclusions
} 
its trading partners ${ }^{3}$, Looking into currency choice in such country may shed light on the global questions of the dominancy of certain currencies in the world economies. Therefore, and taking into account the aim of investigating the strategic determinants, I concentrate my analysis as the contrasting the choices of bilateral trading parner currencies versus the vehicle currency consideration.

Using the dataset firm identifiers, I investigate in greater detail the realisation of the strategic determinants at the country and firm level and how they are effecting the choice of currency among the exporters. Notably, these determinants have different direction of the effect at the two levels. When a country has greater bargaining power, the transaction is more likely to be priced in the currency of the trading partners - PCP or LCP; when a firm has greater bargaining power, the application of the VCP is more probable. By looking first time at the aggregate and firm-level variables jointly, the result of this research points out the importance of taking into consideration the market structure of the industries when I look at the currency choice as as a macroeconomic question that determines the response of the trade balance, domestic price levels and overall international competitiveness of the economy to the change in the exchange rate.

The increase in the probability of LCP and PCP when countries trade more is consistent with the theoretical prediction of Bacchetta \& van Wincoop (2005) that the overall presence of the domestic firms at the market overturns the optimal currency choice. More particularly, one can assume that there are more firms exporting, including smaller exporters, so they can either use their domestic currency and be insured against any exchange rate changes or they can use destination currency and be insured against their market position relative to their competitors at the local destination ${ }^{4}$ By-turn, the more the firm trades, the more it will use VCP as it cares less for the marginal profit and more for the total profit - therefore it will be willing to take more exchange rate risk (use less domestic currency) and given the global availability and usage of a couple of currencies that constitute the VCP, they choose VCP. Along with this result, I also find evidence that VCP is being applied for the relatively cheaper sales. These findings support the theory of "bargaining over invoicing", theoretically formulated by Goldberg \& Tille (n.d.).

The diverse effect of the strategic currency choice determinants implies that both policy-makers and researchers cannot (and should not) disregard the firm-dimension when they are making inference on currency choice. There will be different currency pricing behavior in the industries that have many or few exporters that do many or few transactions - therefore there will be different transmission of the exchange rate shock between these industries. Another result of looking into the strategic currency choice with the information on the firm identifyers is that I observe the firm-level "coalescing" behavior: the firms tend to mimic the currency pricing that is being applied by its competitors. The more diversified is the portfolio of the competitors, the more likely is the exporter to diversify too.

The closest research to this paper would be the papers by Chung (2015) and (Devereux et al. 2015). The former concentrates on the role of intermediate inputs in firm-level currency choice, the latter asks a question how market shares of the firms - both the exporters and importers effects the exchange rate pass through and choice of currency. My findings are consistent with both of the papers while giving a deeper insight to the theoretical findings of (Devereux et al. , 2015). In general, this paper is also connected to the vast literature on the exchange rate pass-through in international trad ${ }^{5}$; the most

\footnotetext{
${ }^{3}$ Other countries which had roughly similar data available were United States, Canada and United Kingdom. All these countries either have strong currency which is used by other countries, or their trade is mostly concerned with one single country that has the strong currency (Canada).

${ }^{4}$ When the exchange rate shock is realised the firm that has the currency portfolio as the currency portfolio of the market keeps its relative position to its competitors - the "coalescing" effect of currency pricing.

${ }^{5}$ The non-exhaustive list will be Berman et al. (2012); Amiti et al. (2014); Novy (2006); Gopinath et al. (2008); Devereux \& Yetman 2010); Ceglowski (2010); Korhonen \& Vilmi (2014)
} 
related paper will be the firm-level research of (Berman et al., 2012$)$. The low exchange rate pass-through of the bigger exporters may be explained by their higher application of VCP. When there is more VCP used in trade, the reaction to the destination-specific exchange rate shock trivially goes down.

Some recent survey studies on currencies in international trade (Ito et al. 2010 , Friberg \& Wilander, 2008) established that VCP is more dominant than anticipated by the theory. The research of Goldberg \& Tille (n.d.) and Goldberg \& Tille (2008a) formulated the overall framework to asses the main determinants of the currency choice in international trade and, separately, a model that embraces the contractual nature of currency choice decision in international trade. The monopolistic competition model of Devereux et al. |l (2015), and research of Chung (2015) concentrate on the production-chain aspect of currency choice decision.

I concentrate on the strategic aspect of currency choice not merely because of the unavailability of the import data (which is available for the mentioned above tests), but because most of the papers up to date disregard the contractual nature of international trade, where exporters have to sign an actual contract to sell their goods. An exporter needs to sell his good at a destination competing for the contract with local producers and other exporters - this competition includes the price/quantity dimension, but also the currency of the sale. In contrast to the common two-choice models and test, this paper brings strategic determinants into the real data with the three choices that are available to the exporters.

The currency pricing of the transactions matters a lot for the exporting/importing activity of any given firm: the exporter is exposed to different exchange rate fluctuations, that might eliminate the profits of the transaction whatsoever; the importer still needs to convert any other currency into its domestic since that is (generally) the currency in which the good is realised at the domestic final consumption. Dealing with currencies (other than your domestic typically) the firm needs to make (or not) special arrangements on the financial side of the operations - opening a new account at the bank is costly, whereas if there is none there could be currency mismatch and profits will be altered more. Depending on the type of financing of the transaction, it also matters as the sum in the aforesaid currency will take time to arrive to the account after the deal was signed and the good is shipped (Samiee \& Anckar, 1998). Brol et al. (2006) show that different elasticities of risk aversion for exporters can channel the exchange rate shocks differently, resulting in gains and losses in utility from the same exchange rate shocks for different firms.

In a broader sense, this paper is connected to the "pricing to market" literature?, but in a more disaggregated level, where I investigate how strategic forces lead the firms to implement heterogeneous currency pricing at the same destination. The existence of multiple possible sellers/buyers for the same good at the same destination and the possibility of implementing three different types of currency pricing could lead to increase in hetergoneity in exchange rate pass through.

This paper discerns from other papers that attempt to study the currency choice due to several facts: (i) the empirical test of joint micro- and macro-determinants, including the new developing brunch of strategic currency choice determinants; (ii) the viability of the test arrangement due to the three possibilities in contrast to the conventional two choice models and papers; (iii) the exploration of the bargaining ${ }^{6}$ and competitive nature of international trade and decision on currency choice as a consequence of that. The link between the bargaining and competitive nature and currency choice is of particular importance, since this sheds light on the heterogeneous response between industries, countries and country-pairs to the same exchange rate movements.

On top of showing the importance of the strategic currency choice determinants, this paper indicates that the existence of the VCP should not be disregarded both in the

\footnotetext{
${ }^{6}$ Implying the bargaining over the terms of the contract.
} 
empirical and theoretical domain as, for such emerging economies (in this example Russia) and for majority of developing countries, vehicle currency pricing is the main applied choice of the exporters. The strategic motives, availability of the VCP, along with few destinations where many exporters act, may increase the use of VCP even more, making exporters exposed to the non-destination related exchange rate shocks. This implies byturn that many exporters are opened to the monetary shock that is not coming from either their domestic economy nor their trading partners, obstructing the development of the new trade linkages.

The paper also provides evidence that the increase of bilateral country trade increases the usage of the currencies of bilateral partners in trade between these countries. This implies that the agreements that were signed in order to alleviate the relience on the VCP will have the desired effect in just some industries - namely, where the countries have many exporters engaged in the bilateral trade.7

In this paper I present a unique three-choice test on the firm-level data, which up to my knowledge, has never been done before. Till present moment both economic theory and empirics - with the notable exception of (Goldberg \& Tille, 2008a b; Chung, 2015) - was either limited to considering a two-choice models, where only the currencies of the trading partners have been at the question, or was overlooking the microeconomic and bargaining motivations.

The paper is organized as follows. Section 2 provides the literature review and discusses the main determinants behind the currency pricing predicted by theory. Section 3 describes the data and documents stylized facts on currency pricing. Section 4 describes the methodology. Section 5 provides the results. Section 6 summarizes the conclusions and discussion.

\section{Conceptual Framework and Literature}

The exchange rate shock exposure is conditioned on the choice of currency, and the determinants and effects of currency choice has been long debated.

The debate in the macroeconomics field has determined the importance of currency choice in a number of relevant questions, such as - currency choice effecting the volatility of the exchange rate (Betts \& Devereux, 1999), alter the optimal monetary policy (Devereux \& Engel, 2003) and overturn the predictions of the main economic fundamentals Betts \& Devereux (1999).

One of the first recordings of the currency pricing patterns in trade goes back to Grassman (1973, 1976) research who stated the fact that trade of the manufactured goods between the developed countries tends to be invoiced in the PCP. Another finding of the epoch was that trade of differentiated products between developed and developing countries tends to be priced in the developed country's currency was backed up by Page (1977, 1981). Most of the research has been taking the exchange rate variability as the main driving force of application of the diverse currencies by the firms.

The conventional facts first recorded in the literature on currency pricing were found to be challenged in the recent decade when the empirical evidence was acquired. More recent research (Ito et al. , 2010; Friberg \& Wilander, 2008, Bacchetta \& van Wincoop, 2005: Goldberg \& Tille, 2008a) has indicated that there should be other considerations accounted for in the currency pricing decision.

The first firm-level studies to look at the currency choice decision at the level of the firm - Ito et al. (2010) and Friberg \& Wilander (2008) - indicated that Japanese and Swedish exports were not following the so-called "Grassman law" of currency pricing and the question of the currency pricing determinants was once again put on the table.

\footnotetext{
${ }^{7}$ This has been a clause, and more recently a goal of the signed treaties between almost all BRICS, and other developing and emerging countries such as Kazakhstan, Australia, United Arab Emirates, and in process those of Japan, Turkey, Iran.
} 
Altogether, the proposed determinants can be summarized in the three groups: micro, macro and strategic. This paper concerns with the latter group of determinants, but nevertheless this section also presents a brief overview of the other two.

\section{Macro determinants}

One of the big questions of currency choice in international trade is the high presence of USD in trade between the countries that do not trade much with the United States 8 . This question is addressed by Rey (2001) as prevalence of a single currency ("vehicle" currency) in international trade being the result of the low transaction costs of the aforesaid currency.

In the recent years the importance of the destination market structure has been raised as an important determinant of the currency choice. The influence of market-structure related parameters was combined into the notion of coalescing motive of currency choice by Goldberg \& Tille (2008a). The rationale behind is that to insure the most stable position in the destination market a firm needs to mimic the portfolio of currencies that is used on the destination market of the certain good by other firms.

The "coalescing" motive can be illustrated on the fact that homogeneous goods goods that are relatively easily substituted within brands like wheat, rice, coffee - are world-widely priced mostly in USD Grassman (1973); Goldberg \& Tille (2008a b); Novy (2006).

Volatility of the exchange rates, and consequtively, the type of ER arrangement, appear to be one of the obstructing forces in international trade, though some research has found mixed evidence of the magnitude of the effect (Auboin \& Ruta, 2013). It is important to take into account fixed exchange rates and other special arrangements on the exchange rate regimes, as they have different transmission of the exchnage rate shock.

The most recent research deals with the special arrangements of payment systems between the countries ?. The availability of the payment systems aimed at the currency settlements between firms in Argentina and Brazil effect the currency pricing making them more likely to apply bilateral trading partners' currencies.

\section{Micro determinants}

Most of the micro literature is concerned with the exchange rate channelling effect of currency choice. The exchange rate is repeatedly indicated as having a significant impact on the international trade (Hericourt \& Poncet, 2012), that may be different for heterogeneous exporters (Berman et al. 2012), but there could exist potential gains from "pooling" different currencies in the firm activity via their risk elasticities (Brol et al. $2006)$.

The first microeconomic determinant brought up in works of Novy (2006); Goldberg \& Tille (2008b); Chung (2015) is the intra-firm hedging behavior. Firms that use imported inputs use more non-domestic currencies than the ones that produce only from domestic resources. Research on American data of Amiti et al. (2014) shows that there is different durations of price-adjustment and exchange-rate pass-through between the non-USD and USD transactions.

Ito et al. (2010) showed that there is different currency pricing implemented between the firm and its affiliates and other companies, as they follow their own arrangements in payments. The customs data at consideration in this paper does not have information on the customer id-s, but the ownership data on the exporters can be matched to about $60 \%$ of the firms. In the robustness checks I look into whether the currency pricing differs between private and state-owned companies with the underlying assumption that the state-owned companies are less likely to have foreign affiliates.

\footnotetext{
${ }^{8}$ see, for example, Wilander $(2005)$; Ito et al. 2010$)$; Goldberg (2005)
} 
The importance of the import-to-export currency match for exchange rate pass-through is being tested on Russian data in a follow-up paper to this one Kuzmina et al. (n.d.), where I and my co-authors match the import customs data to the export data over the horizon of 7 years.

The more general statement on hedging behavior is that the firms engaged in international trade will choose the currency that has the highest utility in exchange rate movements. It should be noted that with the expansion of the supply chains in the recent decades, some production chains became very tangled and hard to trace, and these co-movements may result in greater likelihood of choosing the vehicle currencies such as USD and EUR.

One should note that the exchange rate movements could be financially hedged against, but as research of Martin \& Mejean (2012) showed, even in such developed and internationally active economies as France, only some [biggest] firms implement financial hedging and only to some transactions. Therefore, looking at the economy of Russian Federation, this paper assumes that there is no financial hedging implemented by an average exporter.

One of the working microeconomic results used as an assumption in this paper is that there is the currency set for the invoice is the same that is used for settlement. This was true in overwhelming majority of the firms in research of Friberg \& Wilander (2008) and therefore is assumed to be an appropriate assumption.

\section{Strategic determinants}

In order for a firm's good to become an exported good, the firm needs to sign a contract with its customer that will execute the sell of the good at a foreign market. When signing a construct, the parties (the seller and the buyer) need to come to an agreement on price, quantity and currency of the good that will be sold. The terms of the contract are dependent on whether there exist outside options for the deal - if there could potentially be another buyer or a seller, and how many of them exist. This relates the currency choice to the two aspects of strategic determinants - bargaining and competitive nature of international trade.

The strategic determinants are the outcome of interaction of bargaining powers of the trading parties on the market. The most recent research (Friberg \& Wilander, 2008, Goldberg \& Tille, 2008a b, n.d.) indicated that the conventional idea of unilateral exporter bargaining power over the currency is faulty, as the actual contract is being bargained over (price, quantity, currency) combination and therefore both the bargaining powers of the importer and exporter are considered when making a decision on the currency. If bargaining powers are asymmetric and parties have different preferences, the currency choice is being determined in favor of the party holding higher bargaining power, and therefore can be not-optimal for the second party. On the terms of the transaction, the bargaining power determination comes down to two aspects: relative importance of the importer to the exporter, relative importance of the exporter to the buyer.

Building on the insights of the current research, this paper differentiates the existence of the aggregate (country) and individual (firm level) bargaining powers:

- Bacchetta \& van Wincoop (2005) has indicated the higher presence of the domestic firms at the destination overturns the optimal pricing decision. Therefore when an exporter is trading to a destination where the home country is the major supplier of the good, it will hold higher bargaining power over the the currency choice. Similar logic can be applied to the only consumer of a country's exports.

- Bargaining model of Goldberg \& Tille (n.d.) points out that as the volume of importer's purchases grows, the importer gains higher bargaining power over the currency determination, as she represents higher share of the exporter's sales; at the same time if there is only one exporter of the good with multiple possible consumers, then the importer's bargaining power will grow less. 
The differentiation between the existence of the two different types of bargaining powers allows to get an important result of this paper: the bargaining powers on each level are realised differently.

Goldberg \& Tille (n.d.) is the first paper that is incorporating the firm-level bargaining framework into the currency choice. Apart of having a two-choice models that neglects the existence of the third choice, another assumption of the model is that there is no effect of the production of products for every transaction on the marginal costs of production of others - meaning there is no spill-over from the production for each of the contracts. These assumptions allow the model to be tractable, but they may oversimplify the reality. In empirical investigation I argue that it is important to look at the more aggregate situation while looking at the firm-level determination.

Looking at the data on industry level is more widely used as it is more applicable for policy determination and, additionally, the industry-level data became available earlier. I use the results of the two-choice model of Bacchetta \& van Wincoop (2005) as the motivation for our test: when there is greater presence of the home companies at the destination, the currency choice of an individual firm may be changed.

This brings in another part of the strategic bargaining arguement - the domestic competitors' presence at the destination. As Bacchetta \& van Wincoop (2005) argue that high home presence leads to a different optimal choice, this leads not only to consideration of the "domestic" presence, but also the "domestic competition" presence: a firm observes the home competitors selling at the destination, and this can effect the currency choice. This is partially linked to the "coalescing" behavior, but deals with the more competitionenforced determinant. I assign firm-level "coalescing" into one of the strategic currency choice determinants.

Foresaid studies has majorily lacked either the availability of the third - vehicle currency - choice or consideration for the fact that the actual decision over the currency is done at the firm level. This paper attempts to address both of these shortcomings in the current scientific literature and shed light on the determinants of the currency choice. The main contribution of our paper is that the strategic determinants are not only relevant for currency choice, but also - due to different realisation at thecountry and firm levels - may be partially accounted for the high presence of the vehicle currencies in international trade.

All in all, the strategic determinants of the currency choice sums up to three parameters:

- the country bargaining power: higher country presence can influence the optimal currency choice for individual firms

- the firm bargaining power: relates the bigger size of the purchase to greater willingness to accept risk due to lower marginal risk

- the firm-level " coalescing" effect: the diversification of portfolios of competitors leads to a given firm's greater diversification

Utilizing the unique type of data - the transaction track decisions on currency choice with unique firm identifiers - this paper presents a sophisticated test on the strategic currency choice determinants, and highlights the importance of the startegic determinants, as they are realised in the different way at the country and firm level. This indicates the need to take into account the firm-level currency decisions when investigating or assessing currency denomination related questions: the same aggregate policy may trigger diverse firm-level response, making the transmission of the policy different.

The most recent study that touches upon what I define as strategic determinants of currency choice is Devereux et al. (2015). The research formulates a monopolistic competition model that focuses on the market shares of the importing and exporting firms and how these shares effect the exchange rate pass-through into import prices in presence of the currency choice. This paper is supporting to theirs in some way, as I also 
investigate the importance of the market shares of the firms, but instead of limiting my analysis to the exchange rate pass-through investigation, I look more into the currency choice determination while extending the choices to three (LCP, PCP, VCP) possibilities.

This section has presented the literature survey and outlaid the main theoretical motives that have been formulated for the currency choice in international trade. Special attention is paid to emerging literature and rationale behind the strategic currency choice determinants. The next session we describes the data that is used.

\section{Data}

\subsection{Data sources}

The main source of data is Russian customs database with population of transaction-level information. The information reported is transaction per firm, per product $\mathrm{t}^{9}$ (10-digit HS), per destination. Per each transaction the value is reported along with the specific currency of the transaction.

The firm identifier is observed (or a physical person, but those observations are dropped for our research) that is performing the export transaction. The paper concerns only the products that are originated in Russia, therefore the "re-export" is eliminated - as they are likely to be the exports of previous periods that got returned. Due to the absence of the customer identifiers, I can not observe if the transaction is a part of a sell to the same buyer or a part of the same contract. An assumption is made that every transaction is a separate contract with a separate buyer, and lalternatively perform an estimation when proxying for cinsumer based on the unit values.

One of the robustness checks uses only the 40 most popular (either by count or by value) destinations in our dataset, which account for over $90 \%$ of trade. Filtering rare destinations could potentially take care of a mutual lack of liquidity faced by the trading parties when performing a selling to one of the filtered destinations, and the exporters/importers cannot get easy access to (or dispose quickly) the currency. The choice of the exporter is then effected by the inability to go for LCP and PCP, whereas the main goal of this study is to investigate the relation between these choices. Analogous logic is applied when performing the robustness check with only CIS countries.

For the main test results I keep the full population of transactions, but omit oil and gas industries of the Russian exports for the robustness check.

All transaction values are converted into the US dollars for compatibility. The conversion is done based on the established daily exchange rate. In case there was recorded a correction to the registered value of shipment, the correction is added to the value based on the exchange rate in the month that the correction has taken place 10 .

Some shipments are excluded from the data investigated, as there is no country of destination reported, private (physical person) is exporting, incorrect tax payer number is stated or the currency of the transaction is not reported. The exclusion constitutes to about $15 \%$ of the transactions, roughly evenly distributed within the observed period. Also the transactions below 500USD ${ }^{11}$ are disregarded if they are not a part of the series of the transactions of the similar size. July and August 2007 are omitted, as the data quality for these months was very low, and relatively only few observations were left after cleaning in these months. Some data entries had to be omitted as there was no relevant entry in COMTRADE at the destination even for HS4 level.

\footnotetext{
${ }^{9}$ Using the 6-digit universal HS, Russian firms report 10-digit classification system TNVED, which provides more descriptive information of the product

${ }^{10}$ The correction of the customs declaration deals, as according to the specified law and regulations, with the incorrect filing of the declaration, changes in contract attributes, returns, and other circumstances which deal mostly with transportation and contractual obligations on delivery.

${ }^{11}$ This is an commonly used value that represents the need to discard the single "sample" transactions.
} 
The HS2 industries for which there are less then 1000 transactions reported are omitted in order to satisfy the variation requirements in estimations.

Country-specific macroeconomic variables - GDP, inflation, CPI - are taken as reported by the World Bank, the Penn World tables and IMF IFS.

The exchange rate variation is calculated based on the monthly averages computed on the data provided by CBR (Central Bank of Russia). The exchange rate reported by the CBR might have a slight difference with the market one, but captures daily fluctuations to full extent.

The sample is not restricted to manufacturing, therefore the wholesalers are included. The selection of manufacturing industries is left to the robustness checks. The initial dataset of roughly 10,9 mln transactions over the observed periodafter cleaning is reduced to 8,5 mln observations. The loss of information is not found to be systematic.

The general correspondence with COMTRADE imports is around 90\%. The database covers the population of all individual export transactions from Russian Federation between the 1st January 2005 and 31st December 2009.

\subsection{Data breakdown}

Table 1 represents the exports decomposition by region in value over the whole observed period. The main export destination is EU with $92.03 \%$ of exports being basic metals and minerals. In general, the exports of basic metals and minerals are overwhelming majority of total exports (about 85\%). This seconds the conventional knowledge that Russia is an resource-exporting country. By count decomposition in Table 2 though presents CIS (Commonwealth of Independent States) as a major export destination of Russian exporters $(44.62 \%)$ whereas the EU accounts only for $15.90 \%$ per cent of transactions by number.

This fact represents the long-established relations between the "Soviet Block" countries as a much higher number of the smaller transactions from higher number of exporters exist for them, whereas with the big advanced economies the majority of the transactions are less frequent but are of much greater value coming from the big exporters.

The rightmost column depicts the industry decomposition of Russian exports. The decomposition by value is highly skewed toward the "basic metals and minerals" category, whereas by count it compiles to less than $24 \%$. This represents high value added of the exported goods. Notably, except for the same pattern is being represented in the exports of machinery ( $1.72 \%$ by count and $11.30 \%$ by value), all other industries show an opposite pattern.

In table 1 I present the size and percentiles distributions of currency pricing by average size and average count among the exporters of different size. Firm size is counted through counting the number of product-destination pairs for each firm. Quarter of all the firms interacts only with one product-destination, which supports the common knowledge of empirical trade. Several facts should be documented from the general statistics:

- Small exporters use LCP more frequently than big ones.

- There is some correlation between the size of the exporter and the relative number and size of the transactions the exporter is doing.

- There is a high and increasing usage of VCP for the exporters all types.

The next section 4 explains the methodology of the test and the construction of all variables in the test, paying greater detail to the construction of the novel variables that test the strategic currency choice determinants.

\section{Methodology}

This section first provides the specification of the main model in general terms. Then explicit explanation of every variable in question is presented, with some fuller explanations 
in the Appendix.

As explained above, this paper assumes the same currency for the transaction, invoicing and settlement following Friberg \& Wilander (2008) research results - this is referred to as "currency pricing" or "currency invoicing" interchangeably. The assumption of common currency for three different operations is intuitive, as for most of the cases, the firm invoices in the currency set in the contract and receives the payment in the currency written in the invoice, which (in most of the cases) is replicating the currency written in the contract.

Each firm is indexed with $f$, exporting good (HS6) $p$ to destination $d$ in period $t, k$ is the subscript for currency, where $k=(h, v, l)$, where $h$ - "home" is PCP, $v$ - "vehicle" is VCP, and $l$ - "local" denotes LCP. Referring to a currency choice $\mathrm{k}$ on the firm- or industry-level implies any combination of currencies used in the export activity, where corner solutions are to price completely in VCP, LCP or PCP. The data suggests though, that all industries (HS-6 level), and most of the firms use at least two currency pricings. As in most of the cases there are multiple transactions from the same exporter to the same product-destination in the same currency, index $t r$ is used to differenciate these transactions. I drop the time subscript for the brevity.

As currency choice consists of three possibilities, Multinomial Logit Model is used to test the relevance of the currency pricing determinants. The left hand side of the all the tests performed represents the mutually exclusive choice of the currency pricing. Therefore, the dependent variable is a categorical variable, where choice curpricing $=0$ represents producer currency pricing PCP, curpricing $=1$ represents local currency pricing LCP and curpricing $=2$ represents vehicle currency pricing VCP. There is no order dependency, and the values represent the mutually exclusive exhaustive choice.

The simplified version of the multinomial logistic regression takes full form of:

$\operatorname{Pr}(P C P, L C P \mid V C P)=M N L($ Strategic_determinants, Micro_determinants,

Macro_determinants)

Table I: Summary of the main currency choice determinants and proxies for them

\begin{tabular}{|c|c|c|c|}
\hline \multicolumn{2}{|l|}{ Currency choice motives } & Country-level variables & Firm-level variables \\
\hline Strategic determinants & $\begin{array}{l}\text { Seller } \\
\text { Bargaining }\end{array}$ & Importshare ${ }_{d, t}^{p}$ & Seller_barg $g_{f, d}^{t r}$ \\
\hline & $\begin{array}{l}\text { Customer } \\
\text { Bargaining }\end{array}$ & Exportshare $_{t}^{p}$ & $\begin{array}{c}\text { Cust_barg } g_{f, p, d, t}^{t r} \\
\text { dAboveMed } d_{f, p, d, t}^{t r} \\
\text { Diversification }{ }_{t}^{p, d}\end{array}$ \\
\hline Micro determinants & & $\begin{array}{l}\text { USDhed } \\
\text { EURhed } \\
\text { Importint }\end{array}$ & $\begin{array}{l}g e_{p, t, d} \\
g e_{p, t, d} \\
\text { ensity }_{p}\end{array}$ \\
\hline Macro determinants & & $\begin{array}{r}\text { Walras } \\
\text { Refce } \\
\text { Eurozo } \\
\text { Coefv } \\
\text { Yea } \\
\text { Destino }\end{array}$ & $\begin{array}{l}\operatorname{con}^{p} \\
n^{p} \\
n e_{d, t} \\
a r_{t, d} \\
r_{t} \\
\text { tion }_{d}\end{array}$ \\
\hline
\end{tabular}


Table 1 below presents the full set of variables used in the estimations, split by the groups according to types of variable controls. Subsections below describe the construction of the variables in detail, with full multinomial logit specifications of the tests with full lists of variables in the Appendix I.

The subsections below describe more thoroughly the construction of each variable.

To capture the within industry correlations all regressions are run with the industry and year clustered robust standard errors on time-industry (year-HS6 level). Changing clusters to HS4-year does not change the results, sothe more disaggregated level of HS6 is chosen. Time dimension of clusters is taken at the year level, with time fixed effects entering the regression on the yearly level too. The level of aggregation provides with sufficient number of clusters, which increase the estimation precision. Reduction of timeaggregation of clusters to a month does not provide sufficient changes to the results, but incommensurably increases the process of estimation.

All estimations are performed with Region-Income fixed effects instead of Destination fixed effects, except for the robustness check with 40 biggest exporting destinations and CIS countries. This is reasoned by the fact that in order to get the variance matrix symmetric and non-singular, too many observations need to be dropped, therefore I lose the descriptiveness of the results.

For all multinomial regressions I chose the reference group of the VCP pricing (curpricing =2). As explained above, the choice is done in favor of VCP as a reference group, as it captures more the effect of the determinants on the trading partners' economies, which are characterized by LCP and PCP. The motivation on choosing VCP as a reference category is the following:

- Theoretically the domestic currency is preferred by each party;

- Strategic determinants are formulated for the buyer and the seller.

This paper concentrates on the application of the strategic determinants - the bargaining and competition enhanced factors - of currency choice and asks a question what are the drivers of the contracting parties to use the VCP (in most of the cases USD or EUR) for their export transactions.

The coefficients in the result tables represent the loglikelihoods. The positive loglikelihood (relative risk ratios reported upon request) indicates that the increase in the according variable by 1 unit has positive log likelihood effect on applying one of (be it LCP or PCP) the trading partner currencies. The negative sign on the significant coefficient therefore indicates the lenience to VCP when the variable is increasing.

On top of having the two-level test, I also split the sample for all regression based on the median size of the exporter - three product-destination pairs (when I drop the one-time exporters from consideration, the median number of product-destinations rise to five, but the results remain unchanged). Splitting the sample by the size of the exporter allows to test whether there is a certain group of the exporters driving the resulting effects; this consideration is very important due to the non-linear distribution of the exporter sizes in international trade, with more than $60 \%$ on average serving one destination or one product (Melitz \& Ottaviano, 2008).

\subsection{Macroeconomic determinants}

As I am looking into the currency choice by transaction of Russian exporters, I assume that the transaction costs are same for all the exporters, as I control for the common timevariant characteristics through including the time-dummies $Y_{\text {ear }}$. For the robustness check I drop the financial crisis period and look only into 2005-2007.

The coalescing motive is build after Goldberg \& Tille $(2008 \mathrm{~b})$ by constructing a set of dummies according to the Rauch (1999) classification (based on the level of elasticity 
of substitution): organized exchange traded, reference-priced and differentiated good\$ ${ }^{12}$,

Homogenous goods are held as a reference category for the the dummies Walrascon $^{p}$

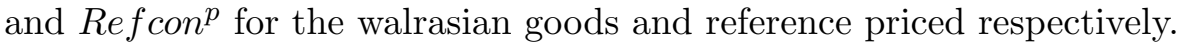

Destination is a dummy that captures the Region-Income level aspect of the destinations in the data. The World Bank classification of countries is used.

Coefvar ${ }_{t, d}$ represents the volatility of the destination currency versus the national currency. The theoretical claim is that the higher is the volatility at the destination, the less likely the exporter to use LCP. The measure is calculated through the variation coefficient in order to dispose the level effects. It is constructed as a rolling coefficient for quarters based on the previous four quarters over the daily reported values ${ }^{13}$. As a robustness check I also perform a rolling coefficient over a 2-year window - the results did not change.

Eurozone $_{t, d}$ is a dummy indicating the EU country. Cyprus, Slovenia and Slovakia have entered eurozone within the observed period, therefore variable is time-variant. Denmark has both EUR and DKK assigned as LCP.

As I do not have the Import Intensity by industry of Russian exports, a set of dummies is constructed for every HS2 category in order to control for how much imports on average is needed for the industry. The assumption here is that the industries that require more imported inputs would be more likely to use currency other than domestic currency. This may be looked at in the framework of the back-and-forth trade where the exporter would use a currency of a country where she gets it imports from so that to "absorb" the exchange rate fluctuations into their cost structure. This is left to the future research with better data to investigate the question more thoroughly 14

\subsection{Micro determinants}

The hedging motive is tested through constructing USDhedge, EURhedge. All dummies are constructed for each 1-quarter period and take value of 1 when the currency (USD or EUR) is a better hedge than the others. Therefore, USDhedge will take value of 1 when it is a (statistically significant) better hedge in the given period than EURhedge, which then has a value of 0 for the relevant period 15

Only two hedging currencies - EUR and USD - are looked at, as they are the most popular vehicle currencies (85\% VCP in the observed period accounts for USD, $14 \%$ to EUR). There is no destination-country-specific measured hedging variable, as other currencies are used as VCP in less then $2 \%$ of the cases.

It should be noted that the financial hedging is excluded only to discussion in the conclusions of the paper. The assumption is that there is no financial hedging done, as it has been documented that even in the economically developed countries financial hedging is used only for some of the big transactions by some of the big exporters (Martin \& Mejean, 2012). Considering the Russian exporters, there is a suspicion ${ }^{16}$ that when financial hedging is employed, it is employed majorly in the transactions between affiliates (or branches), therefore is applicable only to a very limited number of firms.

\footnotetext{
${ }^{12}$ Due to the differences in the composition of the markets of the relevant goods, the goods traded on the organized exchange market would appear to be mostly homogeneous, and for them the price is the main attribute when making a purchase. The reference priced goods are the ones that do not have an organized exchange market, but are close substitutes. The traders can find a reference for the price, and find a seller with the cheapest price, without being overly concerned about additional characteristics. For the differentiated goods the specific characteristics of the product, quality, the "brand" will matter more, leaving the producer with higher price-setting power.

${ }^{13}$ The daily reports on the exchange rates are taken from the Central Bank of Russia, therefore they capture the face-off dynamics of the rates for the firms

${ }^{14}$ The question is explored on the data with import side in a companion paper "Passing on the PassThrough".

${ }^{15}$ See Appendix for the description of the construction.

${ }^{16}$ Based on the talks with real exporters.
} 


\subsection{Strategic motives}

As explained before, the strategic motives capture two aspects of international trade: competition and bargaining. In this subsection first the construction of the variables that proxy for the bargaining part is introduced, and then the construction of variables that measure competition part is explained.

Conventionally, the currency choice determinants have been regarded at the aggregate level. Utilizing the information on the firm identifyers I construct the bargaining variables not only at the aggregate, but also at the firm level. Testing the established theories on the real data I find that the bargaining variables have different direction of the effect at the aggregate and firm level.

The bargaining powers are split in two possible ways: relative power of the seller to the buyer and relative power of the buyer to the seller. All measures are calculated at the HS6 level.

I construct the proxy for the aggregate customer bargaining power as the share of the exports that go to a given destination in total Russian exports of the product $p$.

$$
\text { Exportshare }_{t}^{p}=\frac{\text { Russian_destination_export }}{\text { total_d,t }^{p} \text { Russian_export }}
$$

The value of Exportshare $_{p, d, t}$ is bounded between $[0 ; 1]$, where the value of 1 means that all Russian exports of the product $p$ were sent to destination $d$, decrease of the measure impies that there are other destinations where the goods could have been sent to and therefore the bargaining power of the destination $d$ is lower.

The seller bargaining power is proxied through Importshare $_{p, d, t}^{i}$, which represents the share of Russian exporters in the destination d's imports of product $p$.

$$
\text { Importshare }_{d, t}^{p}=\frac{\text { Russian_import }^{p, d, t}}{\text { total_import }_{\text {COMTRADE }}^{p, t, d}}
$$

The measure is bounded between $[0 ; 1]$, where a value of 1 implies that Russian exporters were the only suppliers to destination $d$ of a product $p$, decrease of the measure implies that there are other destinations that export product $p$ and Russian exporters could be substituted with other suppliers.

This measure will be high at the product-destinations where Russia is one of the main suppliers - for example, Russian Federation supplies over $60 \%$ of European gas, and therefore the bargaining power in Europe of Russian exporters who sell gas is greater than those who sell cars.

Exploiting the firm identifiers I are able to construct similar measures at the firm level:

$$
\text { Seller_barg } g_{f, d}^{t r}=\frac{\text { firm_sales }^{p, d, t, f}}{\text { total_import }_{C O M T R A D E}^{i, t, d}}
$$

Seller_barg $g_{f, d}^{t r}$ represents the share of the given firm $f$ in the imports of the product $p$ at the destination $d$. The greater is the bargaining power of the seller, the greater power he has in setting the currency of the transaction.

As the customer id is not observed, I control for the share of the transaction in the sales of the firm. It could be implicated that every transaction can be treated as a separate customer.

Variable CustBarg ${ }_{p, d, t, f}^{t r}$ represents the transaction share in the firm sales and is calculated as the relative share of the transaction in firms' export of product $p$ to the destination $d$ in year $t$ [17. If a firm has only one customer at a given destination, then he faces high customer bargaining power and is more likely to apply the currency according to the customer bargaining power.

\footnotetext{
${ }^{17}$ As a robustness check we look at Cust_barg_ $2_{f, p, t}^{t r}$ - the share of transaction in all exports of the product of the firm. The results remain the same
} 


$$
\text { Cust_Barg } g_{i, d, t, f}^{\text {tr }}=\frac{\text { transaction }^{p, d, t, f, t r}}{\text { firm_sales }^{p, d, t, f}}
$$

For all the variables the total imports of the product to the destination $d$ are acquired from the COMTRADE database.

Therefore we have different set of variables for the aggregate bargaining measure (Exportshare and Importshare) and firm-level bargaining measure (Cust_barg and Firm_barg). This allows us to contrast the realisation of the strategic determinants at two levels.

As was explained earlier, the currency choice is a part of the bargaining of the firm in a contract. The bargaining is done over three dimensions: (price, quantity,currency). The theoretical framework on the relation of the parameters is scarce in the literature 18 To capture other characteristics of specific contract we build a dummy variable dAboveMed $d_{f, d, t, i}^{t r}$ which takes a value of one if the given transaction $t r$ is higher than the median unit value of the sale of the specific exporter. Unit value is constructed as ratio of price to quantity, therefore the greater it is, the more expensive each unit of the sale is. By using unit values we can cross-compare different products of the same exporter and different exporters.

Referring to the bargaining setup of the contract, it can be assumed that sales that are more expensive than the median unit value are representing smaller sales. In the bigger sales the average price is lower since the seller is willing to compromise the marginal profit for the sake of getting greater total profit. Therefore $d$ AboveMed is one for the smaller sale: 19

Having the firm identifyers, an additional aspect of the currency pricing decision can be assessed - how choices of one firm relate to the practises of other firms. The assumption here is that the more diversified behavior in currency pricing the competitors have, the more diversified a portfolio of a given firm will be. To measure this diversification index of the firm domestic competitors (all other Russian firms at the destination) is used Diversification $_{t}^{-f, d}$ indicates a greater level of diversification of the competing firms at the product-destination. The construction of this variable is the following:

Sharecur $_{k, d,-f}$ denotes the share of the currency pricing $k$ used by all other Russian exporters to the destination $d$ in the given HS4 industry, where product $i$ is classified, in a period $t$ (year):

$$
\text { sharecur }_{i, k, d,-f}=\frac{\sum_{-f} \sum_{t r} \text { transaction_value }}{\sum_{-f} \sum_{k} \sum_{t r} \text { transact, } t, f, t r, k}
$$

Herfindahl-Hirshman Index $H H_{h s 4, d,-f}$ is constructed for each firm at each destinationHS4 product pair in a following way:

$$
H H_{i, d,-f}=\sum_{k} \operatorname{sharecur}_{k, d,-f}^{2}
$$

The diversification measure Diversification ${ }_{t}^{i, d}$ is formed by computing a reverse index to HH index that shows the concentration of shares per each industry at productdestination:

$$
\text { Diversification }_{h s 4, d,-f}=1-H H_{h s 4, d,-f}
$$

For example, if all competitors of the firm Pravdd ${ }^{20}$ exporting a given HS4 product to Switzerland $(d)$ price their sales in $25 \%$ USD and $75 \%$ Swiss francs, will get

\footnotetext{
${ }^{18}$ the notable exception is Goldberg \& Tille (n.d.), but they are bounded in the two-choice world

${ }^{19}$ We leave out of scope of this paper the discussion of the quality aspect of products. For the discussion on the relation of unit values to product quality please relate to Manova \& Zhang (2012)

${ }^{20}$ Hence the subscript is $-f$, denoting "everyone but the firm in question".
} 
sharecur $_{i, v,-d, f}=0.25$ and sharecur $_{i, e, d,-f}=0.75$. Then $H H_{i, d,-f}=0.0625+0.5625=$ 0.625 and Diversification Sh $_{4, d,-f}=1-0.0625=0.375$.

Value of Diversification index is bounded between [0;0.67]. Diversification at zero implies that all HS4 competitors at the destination do extreme currency pricing and price only in one choice, notably $\mathrm{VCP}{ }^{21}$

The coalescing motive of Goldberg \& Tille (2008b) predicts that the greater the diversification of the competitors is, the more diversified portfolio will be.

In the companion paper we investigate the question whether having a more diversified portfolio is more benefitial for the exporters, and leave this discussion out of the scope of this paper.

\section{Dimensions of the Test}

The results in the next section are presented in the following order - the test of the currency choice is performed using both the aggregate and firm-level variables. The findings on the diverse realisation of the strategic currency choice determinants are discussed, along with the heterogeneous exporters aspect of it. As the main specification MNL is used, therefore the magnitude of the effect is hard to be assessed. After reporting the marginal effects, the firm-level determinants of the share of VCP are estimated in an OLS regression, utilizing the average values of the same variables as are used for the MNL estimations. The results of these estimations are aimed on seeing the same directions of the effect as in the threechoice setting.

In order to test the robustness of the MNL results on the strategic currency choice determinants, I perform a number of the robustness checks with limited subsamples, along with splitting the tested variables into the aggregate and firm-level test separately. Most of the robustness checks hold the results on the strategic currency choice determinants, or they provide insignificant result. In conclusions the further implications of the results and policy relevance is discussed.

Brief discussions on the type of robustness checks performed are also reported.

\section{Results}

In previous sections an econometric test that is aimed to capture the influence of the strategic determinants of currency pricing as implied by the existent literature was devised 22 This section describes the realisation of this test on the currency-tracked transaction data of Russian exporters.

As in order to capture the three-choice world the multinomial logit regressions are used, the left hand side of the all the tests performed represents the mutually exclusive choice of the currency pricing with VCP as the reference group. Due to the aplication of the multinomial logit, derived coefficients cannot be represented as elasticities, as they represent the log-likelihood of one of the choices versus the reference group; they determine the direction of the influence of the variables on the choice outcome compared to the reference group. As one mean of the robustness check, the OLS regressions on the share of VCP are performed and the results are reported.

As shown in table 4 the choice of currency is mostly concerned with firm-specific and destination-specific determinants, with the product-specific having lowest explanatory power. This supports the claim that both the aggregate- and firm-level characteristics should be taken into acount. For the purpose of our question, we are interested in how the firm-specific strategic interaction effects the currency choice. In order to further exploit the information on firms, the firm-level data on the number of product-destinations served is used to split the sample by the median number - less than three product-destinations

\footnotetext{
${ }^{21}$ Please refer to Appendix for more explanation on construction of diversification index.

${ }^{22}$ After the data cleaning as described in section 3 .
} 
and more than three - naming the subsamples accordingly "small" and "big" exporters. This split allows us to see if there is different realisation of the determinants by the heterogeneous exporters. Table 5 reports the results of the test on the full set of the determinants on the full population of the currency choices of the exporters, along with the results on the small and big exporters.

In every table columns (1) and (2) the results on the regressions on the full sample are presented, (3) - (6) utilize the information on the size of the firms: [(3) and (4)] on big; $[(5)$ and (6)] on small exporters respectively.

\subsection{Strategic currency choice determinants}

The principal result with regards to the strategic determinants is that they have different effect at the aggregate and firm level:

- When a country has greater bargaining power (Importshare in part of LCP and Exportshare for the both of categories), the bilateral trading partner currencies (PCP and LCP) are more likely to be used;

- When a firm has a greater seller bargaining power (FirmBarg), the vehicle currency (VCP) is more likely to be applied.

The higher likelihood of applying LCP or PCP when the country bargaining powers grow is in line with the Bacchetta \& van Wincoop (2005) idea of the change in the optimal pricing when there is a higher number of the domestic firms at the destination. When countries trade more, they get more exposed to each other's markets and bargaining power - they start using more of each other's currencies. Looking into the heterogeneous exporters dimension, we find that the result is more robust for the smaller exporters: when Russia is more present at the destination, they use more of their domestic and destination currencies, whereas the big exporters are more likely to use LCP, but less PCP.

The actual bargaining powers over the contract are realised at the firm-level and it yields a different result: when a firm has greater bargaining power toward its customer, it is more likely to use more VCP. This finding can be explained through applying Goldberg \& Tille (n.d.) theory of bargaining over invoicing to the three-choice world and scale effect: when a firm sales more, the size of the average sale grows, the firm cares less for the marginal profit, but more for the total profit. This, by-turn, leads to a greater willingness to accept exchange rate risk and therefore abandon the preferred choice of domestic currency. In the presence of the three choice possibility and general dominance of the VCP in international trade, a given firm is more likely to switch to VCP when its seller bargaining power is bigger.

Looking into the heterogeneous exporters, one can see that these are smaller exporters who generate the positive effect of Importshare, whereas the results on other variables Exportshare and FirmBarg stays robust for both of the types of the exporters. This is consistent with the logic explained above - the positive effect of greater trade is sourced mostly from smaller exporters that are more dependent on the currency of their wagebill. The bigger exporters care less about their domestic currency and therefore they are less likely to use more PCP when their country trades more with the destination.

Due to the very complex nature of the currency choice question, traditionally it has been regarded in the context of industry. This diverging effect of bargaining powers of the countries and firms implies that currency choice (to the degree it impacts the exchange rate pass through) should be looked at in the context of the firm-industry composition. As currency choice of the firms remains a firm-level determination, we should look at the distribution of firms within the industry. For example, an industry that applies a lot the VCP will evidently effected differently than the one that mostly LCP, but the same inference could be done on the basis of the number of the exporting firms in the industry - with the latter being much easier to be estimated. 
Looking into dAboveMed variable supports the Bacchetta \& van Wincoop (2005) logic about overturning the optimal currency choice when the the cheaper sales are more likely to be in VCP. As the cheaper sales in our definition represent bigger contracts - the seller is willing to get lower marginal profit for the sake of total profit of the bigger sale - it implies that the selling firm is choosing the VCP for the bigger - and cheaper - contracts, whereas for the contracts where there is high marginal profit it is more likely to choose LCP or PCP. In the main estimation it holds true only for the smaller exporters, but when

Diversification is indicating the existence of the firm-level coalescing behavior - the firms tend to diversify their currency pricing more the more their direct competitors diversify. It is more persistent for the small exporters - more so, the smaller exporters.

The diverging effect of strategic currency choice determinants provide a new channel for assymetry of exchange rate pass through in international trade: bigger exporters will have more intensive use of VCP, and therefore will be less sensitive to the exchange rate shock. This is in line with the findings of the international trade literature 23 and lays out a new channel for the role of different currencies in international economics.

The marginal analysis is presented in table 1. As we are operating with multinomial logistic regression, the coefficients are not elasticities, but the relative log likelihoods. Therefore, the figures indicate the decrease/increase in the relative likelihoods across the whole data or given industries, over the whole dataset. In order to see whether the similar effect is holding for a single firm in the economy, as a form of robustness check the OLS regressions are run.

\subsection{Robustness checks}

Table 7 summarizes the results on the strategic determinants across different robustness checks. The robustness checks are performed in order to see whether there is a certain subset of firms/destinations that is driving the results. The full results of the robustness checks are also reported. As it was described in the Data Description part, basic metals and minerals constitute about $80 \%$ of exports in value, so we exclude that category in order to check if it not that category driving the results. There might particular processes that account for currency pricing during the Financial Crisis that we do not account for. The results hold if we omit 2008-2009 period, which is robustness check "No crisis". The split of the firm size is being done on 75th percentile, as was explained before. This was done due to the fact that the median firm in Russian Federation over the whole period exported only 3 product-destination pairs. We also perform the robustness check with the destination-specific fixed effects (initially we use region-income fixed effects in order to escape the singularity of the variance matrix and the truncation of the sample).

Afterwards, in tables 15 and 16 we use Akaike informative criterion (AIC) and BIC scores to compare explanatory power of the alternative combinations of the variables.

As we have discussed above, using multinomial logit allows as to have a match to the real-world situation of three currency pricing choices faced by an exporter, but we lose on the descriptory power of the test. In order to provide some inference on the magnitude of the discribed above effects on the firm-level, we aggregate our results to the firm-productdestination level through average values of the variables in question:

$$
\begin{aligned}
& \text { shareVCP }_{p, f, d}= \beta_{0 j}+ \\
&+\beta_{1 j} * \text { Importshare }_{p, d}+\beta_{2 j} * \text { Exportshare }_{p, d}+ \\
&+ \beta_{3 j} * \text { AvCustBarg }_{p, f, d}+\beta_{4 j} * \text { AvFirmBarg }_{p, f, d}+ \\
&+\beta_{5 j} * \text { dAboveMedAllDest }_{p, f}+\beta_{6 j} * \text { Diversification }_{p, d,-f}+\beta_{7 j} * \text { Ntrans }_{p, f} \\
& \\
&+ \text { MICROcontrols }+ \text { MACROcontrols }+\epsilon_{p, d, f, t r}
\end{aligned}
$$

\footnotetext{
${ }^{23}$ See $($ Berman et al., 2012$)$ for the most recent findings and an overview
} 
The results of the firm-level regressions are presented in the 6. Across the (1) - (5) different sets of fixed effects are implemented, and the result appears to be mostly robust - the increase in the firm bargaining power increases the share of VCP in the company's basket of currency pricing, whereas the increase of country bargaining power decreases the share of VCP.

\subsection{Other findings}

I find that the type of good indeed matters for the type of pricing being applied, as being predicted by other theories: the more diversified the goods are, the more likely non-VCP currencies to be applied. This is more prevalent for the smaller exporters.

Exporting to Eurozone area makes the application of the LCP more likely - since it is the second most popular VCP in the world and is more used. Transactions to the destinations pegged to USD makes the VCP more likely as the most popular VCP currency is USD.

Hedging variable does not behave as predicted by the theory, but this may be due to the industry-level construction of it ${ }^{24}$ Better hedge in euros and better hedge in dollars increase the likeliness of the use either of PCP or LCP25. This indicates that the firms do not really utilize the hedging possibility itself, but might be seeing it as a better "security" for the transaction in other currencies. Notably, Euro is being a significant form of "insurance" for the smaller exporters, whereas the bigger ones are referring to the USD.

\subsection{Interpretation}

This is a new evidence that indicates that signing RTAs could effect the so-called "dollar dependence" in international trade between countries, but this may be conditioned on the export market structure because of the "love for dollar" paradox. Therefore, the higher change is most likely to be observed in an industry where there is more exporters, and the increase in trade between two countries is least likely to affect currency choice preferences in an industry where there is only one exporter.

We find strong support for theoretical predictions on "hoarding" or "coalescing" behavior of the exporters - meaning that the currency pricing depends on the type of goods being traded (as oil is most likely to be priced in USD because there is a centrilized market of oil trading that quotes the spot price) and on the behavior of the competitors at the destination (if all competitors do LCP, the exporter will also apply LCP). This determinant is even more pronounced when we look at it in the heterogeneous exporters framework - smaller exporters are more likely to use their domestic currency which, controlling for other variables, is their truly preferred choice, as their share of wages in marginal costs is presumably higher.

We record evidence that for a country that does not possess one of the most-used currencies in the world, such as Russian Federation, increase in the volatility of the bilateral exchange rate elevate the probability of the exporters to resort to the vehicle currency pricing as a form of risk-sharing in the transactions.

\section{Conclusions}

This paper addressed the question of importance of the strategic determinants of currency choice in international trade, and showed that they are realised differently at the level of a country and firm. Strategic currency choice determinants are formed from consideration

\footnotetext{
${ }^{24}$ The more intricate investigation of this motive is performed in the paper "Passing on the Pass Through" (work in progress).

${ }^{25} \mathrm{As} 85 \%$ of the VCP is in USD, we might have some biasedness because of the exports to the USA. Though, this relation remained when we dropped the destination of the USA.
} 
of the bargaining powers of the contracting parties and the competition influenced characteristics of international trade. Currency choice matters for channeling the exchange rate shock transmission, and understanding how the exporters are choosing the currencies for their activity aids in forecasting the exchange rate pass through nto import prices and reactions of exporters to the changes in monetary policy.

Using a unique dataset with transaction-tracked currency choice exports of Russian exporters and exporter identifyers, I show that greater country bargaining powers increase the probability of the use of the trading parties' currencies (PCP or LCP) over VCP, whereas greater firm-seller bargaining powers increase the probability of application of VCP. This two different directions of the effect imply that the transmission of the exchange rate shock will be different between different industries depending on the distribution of the exporters in the industry.

The divergent effect of seller bargaining power on choice of VCP among exporters is a result of the existence of the third choice in currency pricing. The increase in probability of LCP/PCP application when trade between countries is bigger is sourced through the increases the bargaining power for all domestic firms - the "default" option of the currency pricing is domestic currency, as that is the currency of the wage bill, the use of dome; the higher firm-seller bargaining power makes the firm choose VCP as a result from greater exchange-rate risk perception - the greater is the sale, the less marginal profit plays role and the more the total profit, which leads to greater acceptance of the exchange rate risk, and - as one can assume there is a wide belief of the wide-acceptance of VCP currencies the seller is choosing VCP.

The support to the bargaining theory of invoicing is provided as we are looking into the firm-level bargaining over currency choice, including the within-firm variation of the currency choice: which currency pricing is applied to the transactions above and below the median value transaction. The relatively cheaper transactions are priced in VCP, while more expensive transactions are priced using LCP and $\mathrm{PCP}^{26}$; the smaller sales exporters prefer to have in the trading partners' currencies, whereas the bigger sales they are willing to go for other currencies, since they can take more exchange rate risk for the sake of securing greater total profit.

Another novel observation the paper delivers is the existense of the firm-level coalescing: the more the competitors diversify the currencies they use, the more diversified the firm's portfolio wll be. This supports the theoretical wisdom that the firms are trying to mimic the portfolio of their competitors in order to be exposed to the exchange rate shock symmetrically.

Different currencies applied in international trade channel the exchange rate differently, and therefore the documented low levels of the exchange rate pass-through for the bigger exporters could be due to the bigger exporters using greater amounts of VCP in their trade. The different realisations of the strategic currency choice at the aggregate and firm level indicate that when addressing currency choice - related questions one should consider the industrial composition of the economy in question.

This paper is one of scarce number of papers that have considered a three-choice model of producer currency pricing (PCP), local currency pricing (LCP) and vehicle currency pricing (VCP) - expanding the usual empirical trade approach of bivariate choice between PCP and LCP. The main contribution of the paper, apart from providing an extensive currency choice test on a country that does not have strong currency, it indicates that strategic determinants are realised differently at the aggregate level - when a country has higher bargaining power, more LCP and PCP is applied, whereas the higher bargaining power of the firm makes the application of VCP more likely.

Evidence for "mimicking" among the exporters in their market currency pricing is also found - the exporters observe what their competitors do and try to replicate similar currency pricing in order to have same exposure to the exchange rate shock.

\footnotetext{
${ }^{26}$ The result is robust in most specifications, but is mostly relevant for smaller exporters.
} 
Based on the unique data this paper has investigated the question of the currency choice determination of the Russian exporters, paying special attention to the realisation of the strategic determinants. The strategic determinants result from the bargaining and competitive side of international trade and have not been studied extensively due to data limitations. This paper on the example of Russian exporters indicated that there is a different realisation of the strategic determinants at the country and firm level. The realisation of strategic determinants in a three-choice setting could be driving further the hegemony of the United States Dollar.

Even though our article has focused mainly on the empirical investigation of the currency choices of the population of Russian exporters, it formed a promising avenue for further research in the area of the exchange rates and international trade. Some aspects of the literature and question some previous findings were discussed and due to the uniqueness of the data the understanding was expanded. Currency choice is an important part of international trade as it channels transmission of the exchange rate shocks. This paper highlights the importance of market structure and strategic considerations in international currency choice. There is a need for further research to understand the formation and impact of currency choice. One of the potential research avenues can include further investigation of the greater use of USD that is being exhibited by the exporters as a result of them getting higher bargaining power and becoming less preferential to their domestic currency. Another question will be to estimate the quanitative effect of having same currency used for imports and exports as lowering the pass-through exhibited by the exporters. 


\section{Bibliography}

\section{References}

Amemiya, TAKeshi. 1981. Qualitative Response Models: A Survey. Journal of Economic Literature, 19:4(December), 1483-1536.

Amiti, Mary, Itskhoki, Oleg, \& Konings, Jozef. 2014. Importers, Exporters, and Exchange Rate Disconnect. American Economic Review, 104(7), 1942-78.

Auboin, Marc, \& Ruta, Michele. 2013. The relationship between exchange rates and international trade: a literature review. World Trade Review, 12(03), 577-605.

Auer, Raphael Anton, \& Schoenle, Raphael S. 2012. Market Structure and Exchange Rate Pass-Through. Tech. rept.

Bacchetta, Philippe, \& van Wincoop, Eric. 2005. A Theory of Currency Denomination of International Trade. Journal of International Economics, 67, 295-319.

Berman, Nicolas, Martin, P., \& Mayer, T. 2012. How do Different Exporters React to Exchange Rate Changes. The Quarterly Journal Of Economics, 127, 437-492.

Betts, Caroline, \& Devereux, Michael B. 1999. International Monetary Policy Coordination and Competitive Depreciation: A Re-Evaluation. Journal Money, Credit and Banking, 32:4(December), 722-745.

Brol, U., Wahl, J., \& Wong, W.-K. 2006. Elasticity of Risk Aversion and International Trade. Economics Letters, 92(1), 126-130.

Ceglowski, Janet. 2010. Exchange rate pass-through to bilateral import prices. Journal of International Money and Finance, 29(8), 1637-1651.

Cheng, Simon, \& Long, J.Scott. 2006. Testing IIA for Multinomial Logit Model. Sociological Methods and Research, 35, 583-600.

Chung, Wanyu. 2015. Imported Inputs and Invoicing Currency Choice: Theory and Evidence from UK Transaction Data. Tech. rept.

Devereux, Michael B., \& Engel, Charles. 2003. Monetary Policy in the Open Economy Revisited: Price Setting and Exchange-Rate. The Review of Economic Studies, 70, 765-783.

Devereux, Michael B., \& Yetman, James. 2010. Price adjustment and exchange rate pass-through. Journal of International Money and Finance, 29(1), 181-200.

Devereux, Michael B., Tomlin, Ben, \& Dong, Wei. 2015 (July). Exchange Rate Pass-Through, Currency of Invoicing and Market Share. NBER Working Papers 21413. National Bureau of Economic Research, Inc.

Friberg, R., \& Wilander, F. 2008. The currency denomination of exports - A questionnaire study. Journal of International Economics, 75(1), 54-69.

FRIBERG, RICHARD. 1998. In which currency should exporters set their prices? Journal of International Economics, 45(1), 59-76.

Fry, Tim R. L., \& Harris, Mark N. 1996. A Monte-Carlo Study of Tests for the Independence of Irrelevant Alternatives Property. Transportation Research Part B: Methodological, 30, 19-30. 
Fry, Tim R. L., \& Harris, Mark N. 1998. Testing for Independence of Irrelevant Alternatives: Some Empirical Results. Sociological Methods and Research, 26, 401-423.

Gaulier, Guillaume, \& Zignano, Soledad. 2010. BACI: International Trade Database at the Product-Level. CEPII, October.

Goldberg, Linda, \& Tille, Cedric. A Bargaining Theory of Trade Invoicing and Pricing. 2013-09.

Goldberg, Linda, \& Tille, Cedric. 2008a. The Micro, Macro, and Strategic Forces in International Trade Invoicing. Federal Reserve Bank of New York Staff Reports, 405.

Goldberg, Linda, \& Tille, Cedric. 2008b. Vehicle Currency Use in International Trade. Journal of International Economics, 76:2(December), 177-192.

GoldBerg, Linda S. 2005. Trade Invoicing in the Accession Countries: Are They Suited to the Euro? Pages 357-393 of: NBER International Seminar on Macroeconomics 2005. NBER Chapters. National Bureau of Economic Research, Inc.

Gopinath, Gita, Itskhoki, Oleg, \& Rigobon, Roberto. 2008. Currency choice and Exchange rate Pass-Through. American Economic Review, 100:1, 304-336.

Grassman, S. 1973. A Fundamental Symmetry in International Payment Patterns. Journal Of International Economics, 3, 105-116.

Grassman, S. 1976. Currency distribution and forward cover in foreign trade. Journal Of International Economics, 3, 215-221.

Hausman, J., \& McFadden, D. 1984. Specification Tests for the Multinomial Logit Model. Econometrica, 52:5, 1219-1240.

Hericourt, Jerome, \& Poncet, Sandra. 2012. Exchange Rate Volatility, Financial Constraints and Trade: Empirical Evidence from Chinese Firms. CEPII.

Ito, T., Koibuchi, S., Sato, K., \& Shimizu, J. 2010. Determinants of Currency Invoicing in Japanese Exports: A Firm Level Analysis.

Korhonen, Marko, \& Vilmi, Lauri. 2014. Competition and exchange rate passthrough. International Economics Letters, 3(1), 5-11.

Kuzmina, Olga, Sokolova, Maria, \& Volchkova, Natalya. Passing on the PassThrough.

Manova, Kalina, \& Zhang, Z. 2012. Export prices across firms and destinations. Quarterly Journal Of Economics, 379-436.

Martin, J., \& Mejean, I. 2012. Invoicing currency, Firm size and Hedging. CEPII.

Melitz, M., \& Ottaviano, G.I.P. 2008. Market Size, Trade and Productivity. Review of Economic Studies, 75, 295-316.

Novy, Dennis. 2006. Hedge Your Costs: Exchange Rate Risk and Endogenous Currency Invoicing. Tech. rept.

Page, S.A. B. 1977. Currency Invoicing in Merchandise Trade. August.

Page, S.A.B. 1981. The Choice of Currency in Merchandise Trade. National Institute Economic Review, 98(November).

RAUCH, J.E. 1999. Networks versus markets in international trade. Journal of International Economics, 48, 7-35. 
Rey, Helene. 2001. International Trade and Currency Exchange. Review of Economic Studies, 68:2(April), 443-464.

Samiee, Saeed, \& Anckar, Patrik. 1998. Currency Choice in Industrial Pricing: A Cross-National Evaluation. Journal of Marketing, 62(3).

Wilander, Fredrik. 2005. An Empirical Analysis of the Currency Denomination in International Trade. 


\section{Table Appendix}

Table 1: Russian Exporters by Destination region and broad industry group, by value

Percent Share In Transaction Value

\begin{tabular}{llllllll|l}
\hline & CIS & China & $\begin{array}{l}\text { East and } \\
\text { SE Asia }\end{array}$ & EU & USA & Middle East & RoW & $\begin{array}{l}\text { Industry } \\
\text { Percent of } \\
\text { the Total }\end{array}$ \\
\hline Agriculture & $3.68 \%$ & $0.04 \%$ & $0.73 \%$ & $0.47 \%$ & $0.29 \%$ & $8.23 \%$ & $1.20 \%$ & $1.57 \%$ \\
Basic metals & $72.67 \%$ & $63.15 \%$ & $86.76 \%$ & $92.03 \%$ & $49.14 \%$ & $81.41 \%$ & $88.73 \%$ & $85.13 \%$ \\
and minerals & & & & & & & & \\
Chemicals & $4.98 \%$ & $13.37 \%$ & $4.17 \%$ & $2.34 \%$ & $6.96 \%$ & $3.37 \%$ & $4.96 \%$ & $4.30 \%$ \\
Leather and & $0.03 \%$ & $0.03 \%$ & $0.01 \%$ & $0.10 \%$ & $0.07 \%$ & $0.01 \%$ & $0.04 \%$ & $0.06 \%$ \\
leather & & & & & & & \\
goods & & & & & & & & \\
Machinery & $6.69 \%$ & $3.84 \%$ & $1.01 \%$ & $0.37 \%$ & $0.87 \%$ & $0.90 \%$ & $1.45 \%$ & $1.72 \%$ \\
Plastic & $2.60 \%$ & $2.40 \%$ & $0.51 \%$ & $0.39 \%$ & $0.37 \%$ & $0.57 \%$ & $0.47 \%$ & $0.52 \%$ \\
Textile & $0.44 \%$ & $0.07 \%$ & $0.05 \%$ & $0.07 \%$ & $0.09 \%$ & $0.15 \%$ & $0.06 \%$ & $0.79 \%$ \\
Transport & $4.45 \%$ & $0.63 \%$ & $1.13 \%$ & $0.13 \%$ & $0.60 \%$ & $0.80 \%$ & $1.08 \%$ & $0.11 \%$ \\
Wood & $3.36 \%$ & $15.73 \%$ & $5.26 \%$ & $3.76 \%$ & $40.85 \%$ & $4.20 \%$ & $1.50 \%$ & $1.09 \%$ \\
Other & $1.11 \%$ & $0.73 \%$ & $0.37 \%$ & $0.33 \%$ & $0.77 \%$ & $0.35 \%$ & $0.52 \%$ & $4.72 \%$ \\
\hline Total & $12.12 \%$ & $4.74 \%$ & $4.68 \%$ & $37.36 \%$ & $2.85 \%$ & $6.38 \%$ & $31.87 \%$ & \\
\hline
\end{tabular}

Table 2: Russian Exporters by Destination region and broad industry group, by count

Percent Share In Transaction Count

\begin{tabular}{|c|c|c|c|c|c|c|c|c|}
\hline & CIS & China & $\begin{array}{l}\text { East and } \\
\text { SE Asia }\end{array}$ & $\mathrm{EU}$ & USA & Middle East & RoW & $\begin{array}{l}\text { Industry } \\
\text { Percent of } \\
\text { the Total }\end{array}$ \\
\hline Agriculture & $11.80 \%$ & $0.27 \%$ & $6.30 \%$ & $3.74 \%$ & $13.79 \%$ & $4.50 \%$ & $7.15 \%$ & $7.88 \%$ \\
\hline $\begin{array}{l}\text { Basic metals } \\
\text { and minerals }\end{array}$ & $19.84 \%$ & $6.73 \%$ & $26.21 \%$ & $29.82 \%$ & $33.48 \%$ & $39.70 \%$ & $33.48 \%$ & $23.84 \%$ \\
\hline Chemicals & $19.84 \%$ & $6.73 \%$ & $26.21 \%$ & $29.82 \%$ & $33.48 \%$ & $39.70 \%$ & $33.48 \%$ & $23.48 \%$ \\
\hline $\begin{array}{l}\text { Leather and } \\
\text { leather } \\
\text { goods }\end{array}$ & $0.22 \%$ & $0.04 \%$ & $0.19 \%$ & $0.88 \%$ & $0.16 \%$ & $0.09 \%$ & $0.28 \%$ & $0.31 \%$ \\
\hline Machinery & $15.97 \%$ & $1.46 \%$ & $8.70 \%$ & $6.72 \%$ & $7.10 \%$ & $5.62 \%$ & $12.33 \%$ & $11.30 \%$ \\
\hline Plastic & $9.69 \%$ & $1.44 \%$ & $4.03 \%$ & $3.38 \%$ & $2.68 \%$ & $3.84 \%$ & $6.75 \%$ & $6.62 \%$ \\
\hline Textile & $2.78 \%$ & $0.14 \%$ & $1.19 \%$ & $1.34 \%$ & $2.00 \%$ & $1.26 \%$ & $2.21 \%$ & $2.01 \%$ \\
\hline Transport & $9.45 \%$ & $0.20 \%$ & $3.64 \%$ & $0.94 \%$ & $2.03 \%$ & $3.97 \%$ & $4.76 \%$ & $5.60 \%$ \\
\hline Wood & $11.11 \%$ & $86.09 \%$ & $35.95 \%$ & $41.77 \%$ & $20.71 \%$ & $32.05 \%$ & $18.64 \%$ & $27.83 \%$ \\
\hline Other & $6.06 \%$ & $0.66 \%$ & $3.27 \%$ & $4.62 \%$ & $8.25 \%$ & $2.01 \%$ & $4.59 \%$ & $4.71 \%$ \\
\hline Total & $44.62 \%$ & $11.26 \%$ & $3.50 \%$ & $15.90 \%$ & $1.90 \%$ & $4.71 \%$ & $18.10 \%$ & \\
\hline
\end{tabular}


Table 3: Transaction Size and Firm Pricing Distributions

\begin{tabular}{llllllll}
\hline $\begin{array}{l}\text { Distribution } \\
\text { the firm sizes and } \\
\text { pricing type }\end{array}$ & $0-25 \%$ & $25-50 \%$ & $50-75 \%$ & $75-90 \%$ & $90-95 \%$ & $95-99 \%$ \\
\hline $\begin{array}{l}\text { Mean } \\
\text { transaction }\end{array}$ & LCP & 117773.9 & 106644.3 & 148789.8 & 201547.2 & 210496.2 & 311179.8 \\
value & VCP & 203208.4 & 155739.6 & 188421.1 & 174836.5 & 177972.1 & 181970.6 \\
\hline Mean & LCP & 2.68 & 8.57 & 25.3 & 73.63 & 195.66 & 311.66 \\
transaction & PCP & 1.87 & 7.32 & 21.98 & 56.22 & 164.33 & 385 \\
count & VCP & 2.97 & 10.51 & 37.86 & 113.19 & 244.93 & 607.95 \\
\hline $\begin{array}{l}\text { Average } \\
\text { share for an }\end{array}$ & LCP & $36 \%$ & $32 \%$ & $30 \%$ & $30 \%$ & $32 \%$ & $24 \%$ \\
$\begin{array}{l}\text { average } \\
\text { fim }\end{array}$ & VCP & $39 \%$ & $40 \%$ & $44 \%$ & $47 \%$ & $40 \%$ & $47 \%$ \\
\hline
\end{tabular}

Table 4: areg for characteristics (R-squared reported)

\begin{tabular}{llll}
\hline & LCP & PCP & VCP \\
Destination & 0.65 & 0.49 & 0.45 \\
Firm & 0.55 & 0.70 & 0.59 \\
HS6 Product & 0.18 & 0.38 & 0.26 \\
Observations & $7,277,340$ & $7,277,340$ & $7,277,340$ \\
\hline
\end{tabular}


Table 5: Joint test of the country and firm level currency choice determinants

\begin{tabular}{|c|c|c|c|c|c|c|}
\hline \multirow[b]{3}{*}{ VARIABLES } & \multicolumn{2}{|c|}{ Full sample } & \multicolumn{2}{|c|}{ Big exporters } & \multicolumn{2}{|c|}{ Small exporters } \\
\hline & $(1)$ & $(2)$ & $(3)$ & (4) & $(5)$ & $(6)$ \\
\hline & PCP & $\mathrm{LCP}$ & PCP & LCP & PCP & LCP \\
\hline \multirow[t]{2}{*}{ Cust_barg } & 0.02 & -0.2 & -0.03 & -0.04 & -0.02 & -0.18 \\
\hline & $(0.03)$ & $(0.06)$ & $(0.08)$ & $(0.07)$ & $(0.05)$ & $(0.19)$ \\
\hline \multirow[t]{2}{*}{ FirmBarg } & $-2.00 * * *$ & $-2.55^{* * *}$ & $-1.98 * * *$ & $-2.31^{* * *}$ & $-1.59 * * *$ & $-3.30 * * *$ \\
\hline & $(0.26)$ & $(0.29)$ & $(0.28)$ & $(0.33)$ & $(0.33)$ & $(0.35)$ \\
\hline \multirow[t]{2}{*}{ Importshare } & -0.19 & $0.49^{* * *}$ & $-0.28^{*}$ & $0.55^{* *}$ & $0.19^{* * *}$ & $0.49^{* *}$ \\
\hline & $(0.15)$ & $(0.21)$ & $(0.14)$ & $(0.20)$ & $(0.08)$ & $(0.27)$ \\
\hline \multirow[t]{2}{*}{ Exportshare } & $0.67^{* * *}$ & $1.16^{* * *}$ & $0.56^{* * *}$ & $1.09 * * *$ & $0.83^{* * *}$ & $1.18^{* * *}$ \\
\hline & $(0.14)$ & 0.24 & $(0.14)$ & $(0.25)$ & $(0.20)$ & $(0.36)$ \\
\hline \multirow[t]{2}{*}{ dAboveMed } & $0.093^{* * *}$ & 0.014 & 0.08 & 0.00 & $0.18^{* * *}$ & $0.08^{* *}$ \\
\hline & $(0.02)$ & $(0.01)$ & $(0.02)$ & $(0.03)$ & $(0.02)$ & $(0.03)$ \\
\hline \multirow[t]{2}{*}{ Walrascon } & $0.88^{* *}$ & $1.63^{* * *}$ & $0.57^{* * *}$ & $1.50^{* * *}$ & $1.89^{* * *}$ & $2.14^{* * *}$ \\
\hline & $(0.11)$ & $(0.22)$ & $(0.12)$ & $(0.27)$ & $(0.16)$ & $(0.32)$ \\
\hline \multirow[t]{2}{*}{ Refcon } & $0.53^{* * *}$ & $1.10^{* * *}$ & $0.27^{* *}$ & $0.77^{* * *}$ & 1.29 *** & $1.90^{* * *}$ \\
\hline & $(0.12)$ & $(0.22)$ & $(0.13)$ & $(0.27)$ & $(0.18)$ & $(0.31)$ \\
\hline \multirow[t]{2}{*}{ Diversification } & $0.57 * * *$ & $0.40^{* *}$ & 0.40 & $0.67 * *$ & $1.53^{* * *}$ & 0.29 \\
\hline & $(0.13)$ & $(0.21)$ & $(0.29)$ & $(0.30)$ & $(0.26)$ & $(0.42)$ \\
\hline \multirow[t]{2}{*}{ USDhedge } & $0.24^{* * *}$ & $0.45 * * *$ & 0.14 & $0.39^{* *}$ & $0.62^{* * *}$ & $0.75 * * *$ \\
\hline & $(0.10)$ & $(0.14)$ & $(0.9)$ & $(0.14)$ & $(0.18)$ & $(0.18)$ \\
\hline \multirow[t]{2}{*}{ EURhedge } & 0.09 & $-0.52^{* *}$ & $0.15^{* *}$ & $-0.41^{* * *}$ & -0.04 & $-0.86^{* * *}$ \\
\hline & $(0.09)$ & $(0.17)$ & $(0.08)$ & $(0.15)$ & $(0.10)$ & $(0.25)$ \\
\hline \multirow[t]{2}{*}{ Euroarea } & $0.83^{* * *}$ & $0.55^{* *}$ & $0.73^{* * *}$ & 0.41 & $1.31^{* * *}$ & $1.30^{*}$ \\
\hline & $(0.22)$ & $(0.33)$ & $(0.23)$ & $(0.32)$ & $(0.53)$ & $(0.68)$ \\
\hline \multirow[t]{2}{*}{ Coefvar } & $-3.28 * * *$ & $2.01^{* *}$ & $-3.16^{* * *}$ & 1.93 & $-4.7^{* * *}$ & 2.52 \\
\hline & $(0.85)$ & $(1.15)$ & $(0.85)$ & $(1.32)$ & $(2.02)$ & $(2.03)$ \\
\hline \multirow[t]{2}{*}{ Constant } & $-2.40^{* * *}$ & $-0.71^{*}$ & $-1.99 * * *$ & -0.49 & $-4.2^{* * *}$ & $-2.27^{* * *}$ \\
\hline & $(0.28)$ & $(0.47)$ & $(0.29)$ & $(0.47)$ & $(0.59)$ & $(0.81)$ \\
\hline Observations & $6,662,349$ & $6,662,349$ & $5,011,741$ & $5,011,741$ & $1,650,608$ & $1,650,608$ \\
\hline Time FE & YES & YES & YES & YES & YES & YES \\
\hline Region FE & YES & YES & YES & YES & YES & YES \\
\hline Clusters & 15048 & 15048 & 14133 & 14133 & 11509 & 11509 \\
\hline
\end{tabular}


Figure 1: Marginal effect of seller bargaining power on possibilities of currency pricings, by selected industries

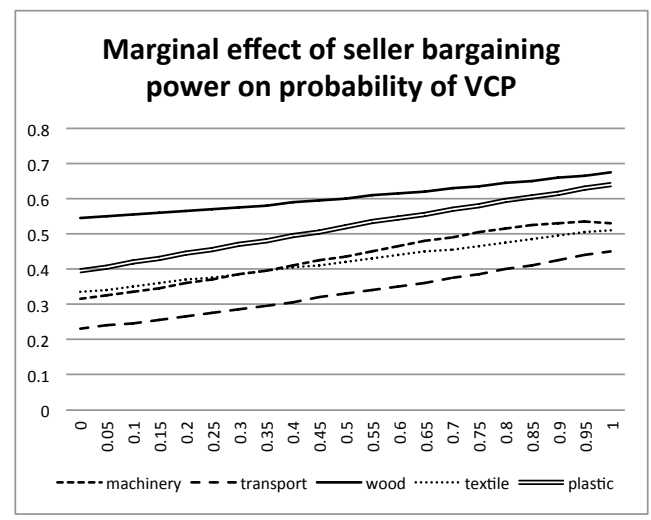

(a) On probability of VCP

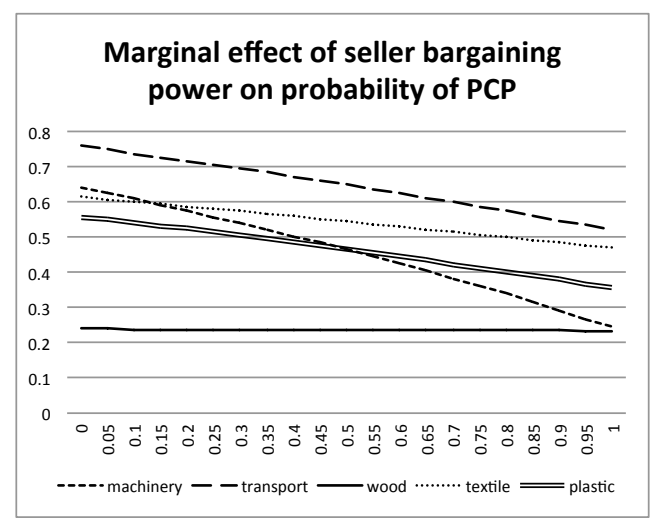

(b) On probability of PCP

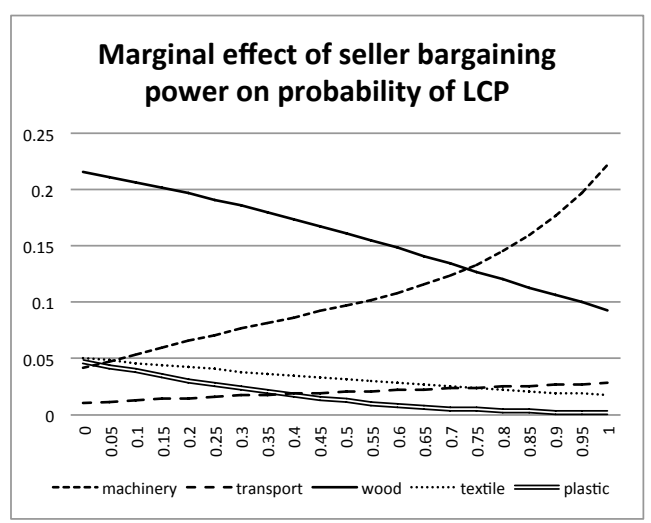

(c) On probability of LCP 
Table 6: Firm-level results

\begin{tabular}{|c|c|c|c|c|c|}
\hline VARIABLES & $\begin{array}{l}(1) \\
\text { shareVCP }\end{array}$ & $\begin{array}{l}(2) \\
\text { shareVCP }\end{array}$ & $\begin{array}{l}(3) \\
\text { shareVCP }\end{array}$ & $\begin{array}{l}(4) \\
\text { shareVCP }\end{array}$ & $\begin{array}{l}(5) \\
\text { shareVCP }\end{array}$ \\
\hline AverageFirmbarg & $\begin{array}{l}0.04^{* * *} \\
(0.01)\end{array}$ & $\begin{array}{l}0.09^{* * *} \\
(0.01)\end{array}$ & $\begin{array}{l}0.09 * * * \\
(0.01)\end{array}$ & $\begin{array}{l}0.08^{* * *} \\
(0.01)\end{array}$ & $\begin{array}{l}0.12^{* * *} \\
(0.01)\end{array}$ \\
\hline AverageCustbarg & $\begin{array}{l}-0.01^{* * * *} \\
(0.00)\end{array}$ & $\begin{array}{l}0.04^{* * *} \\
(0.00)\end{array}$ & $\begin{array}{l}0.02^{* * *} \\
(0.00)\end{array}$ & $\begin{array}{l}0.02^{* * *} \\
(0.00)\end{array}$ & $\begin{array}{l}0.00 * * * \\
(0.00)\end{array}$ \\
\hline Ntrans & $\begin{array}{l}0.00^{* *} \\
(0.00)\end{array}$ & $\begin{array}{l}-0.00 \\
(0.00)\end{array}$ & $\begin{array}{l}0.00 \\
(0.00)\end{array}$ & $\begin{array}{l}-0.00 \\
(0.00)\end{array}$ & $\begin{array}{l}-0.00 \\
(0.00)\end{array}$ \\
\hline Exportshare & $\begin{array}{l}0.01^{* *} \\
(0.00)\end{array}$ & $\begin{array}{l}-0.02^{* * *} \\
(0.01)\end{array}$ & $\begin{array}{l}-0.01^{* * * *} \\
(0.00)\end{array}$ & $\begin{array}{l}-0.01^{* * * *} \\
(0.00)\end{array}$ & $\begin{array}{l}0.00 \\
(0.00)\end{array}$ \\
\hline Importshare & $\begin{array}{l}-0.00 \\
(0.00)\end{array}$ & $\begin{array}{l}-0.03^{* * * *} \\
(0.00)\end{array}$ & $\begin{array}{l}-0.03^{* * *} \\
(0.00)\end{array}$ & $\begin{array}{l}-0.03^{* * * *} \\
(0.00)\end{array}$ & $\begin{array}{c}-0.01^{*} \\
(0.00)\end{array}$ \\
\hline dAboveMedAllDest & $\begin{array}{l}-0.01^{* * *} \\
(0.00)\end{array}$ & $\begin{array}{l}-0.01^{* * * *} \\
(0.00)\end{array}$ & $\begin{array}{l}-0.00^{* * * *} \\
(0.00)\end{array}$ & $\begin{array}{l}-0.00^{* * * *} \\
(0.00)\end{array}$ & $\begin{array}{l}-0.00 \\
(0.00)\end{array}$ \\
\hline Diversification & $\begin{array}{l}0.00 \\
(0.00)\end{array}$ & $\begin{array}{l}-0.02^{* * *} \\
(0.00)\end{array}$ & $\begin{array}{l}-0.01^{* * *} \\
(0.00)\end{array}$ & $\begin{array}{l}-0.02^{* * *} \\
(0.00)\end{array}$ & $\begin{array}{l}0.02^{* * *} \\
(0.01)\end{array}$ \\
\hline USD_hedge & $\begin{array}{l}0.01^{* * *} \\
(0.00)\end{array}$ & $\begin{array}{l}0.01^{*} \\
(0.00)\end{array}$ & $\begin{array}{l}0.01^{* * *} \\
(0.00)\end{array}$ & $\begin{array}{l}0.00^{*} \\
(0.00)\end{array}$ & $\begin{array}{l}0.00 \\
(0.00)\end{array}$ \\
\hline EUR_hedge & $\begin{array}{l}-0.01^{* * *} \\
(0.00)\end{array}$ & $\begin{array}{l}-0.00 \\
(0.00)\end{array}$ & $\begin{array}{l}-0.01^{* * *} \\
(0.00)\end{array}$ & $\begin{array}{l}-0.01^{* * * *} \\
(0.00)\end{array}$ & $\begin{array}{l}-0.01^{* * *} \\
(0.00)\end{array}$ \\
\hline Euroarea & $\begin{array}{l}-0.21^{* * * *} \\
(0.01)\end{array}$ & $\begin{array}{l}-0.17^{* * * *} \\
(0.02)\end{array}$ & $\begin{array}{l}-0.22^{* * * *} \\
(0.01)\end{array}$ & $\begin{array}{l}-0.56^{* * * *} \\
(0.03)\end{array}$ & $\begin{array}{l}0.00 \\
(0.00)\end{array}$ \\
\hline Coefvar & $\begin{array}{l}-0.11^{* * *} \\
(0.03)\end{array}$ & $\begin{array}{l}-0.18^{* * *} \\
(0.05)\end{array}$ & $\begin{array}{l}-0.15^{* * * *} \\
(0.03)\end{array}$ & $\begin{array}{l}-0.21^{* * *} \\
(0.03)\end{array}$ & $\begin{array}{l}-0.14^{* * *} \\
(0.03)\end{array}$ \\
\hline Uniqueppairs & & & $\begin{array}{l}-0.00 \\
(0.00)\end{array}$ & $\begin{array}{l}0.00 \\
(0.00)\end{array}$ & $\begin{array}{l}-0.00 \\
(0.00)\end{array}$ \\
\hline Constant & $\begin{array}{l}0.42^{* * *} \\
(0.01)\end{array}$ & $\begin{array}{l}0.72^{* * *} \\
(0.02)\end{array}$ & $\begin{array}{l}0.77^{* * *} \\
(0.01)\end{array}$ & $\begin{array}{l}0.75^{* * *} \\
(0.02)\end{array}$ & \\
\hline Observations & 660,682 & 660,682 & 660,682 & 660,682 & 660,682 \\
\hline R-squared & 0.96 & 0.89 & 0.83 & 0.84 & 0.82 \\
\hline Time FE & YES & & YES & & \\
\hline FirmProductDestination FE & YES & & & & \\
\hline Destination FE & & YES & YES & & \\
\hline FirmProductYear FE & & YES & & & \\
\hline ProductDestinationTime FE & & & & & YES \\
\hline Firm FE & & & & & YES \\
\hline FirmProduct FE & & & YES & YES & \\
\hline TimeDestination FE & & & & YES & \\
\hline
\end{tabular}

Robust standard errors in parentheses

$* * * \mathrm{p}<0.01, * * \mathrm{p}<0.05, * \mathrm{p}<0.1$ 
Figure 2: Marginal effect of strategic currency choice variables on the share of VCP

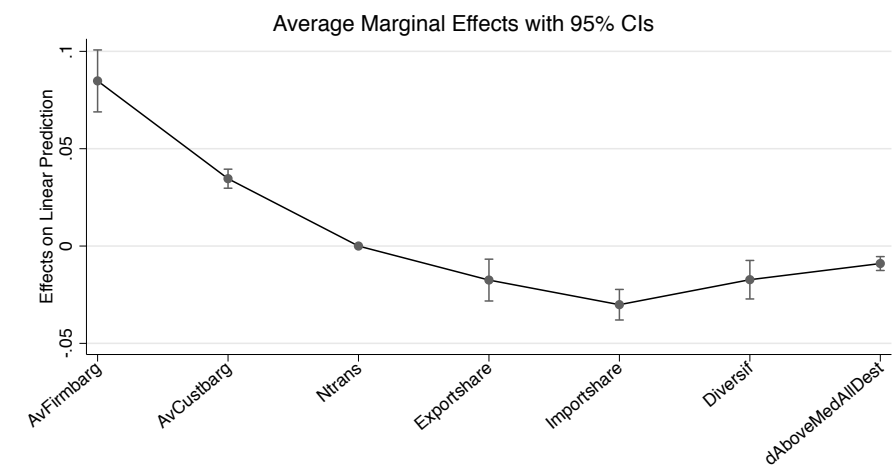

(a) On probability of VCP

$[\mathrm{h} !]$ 


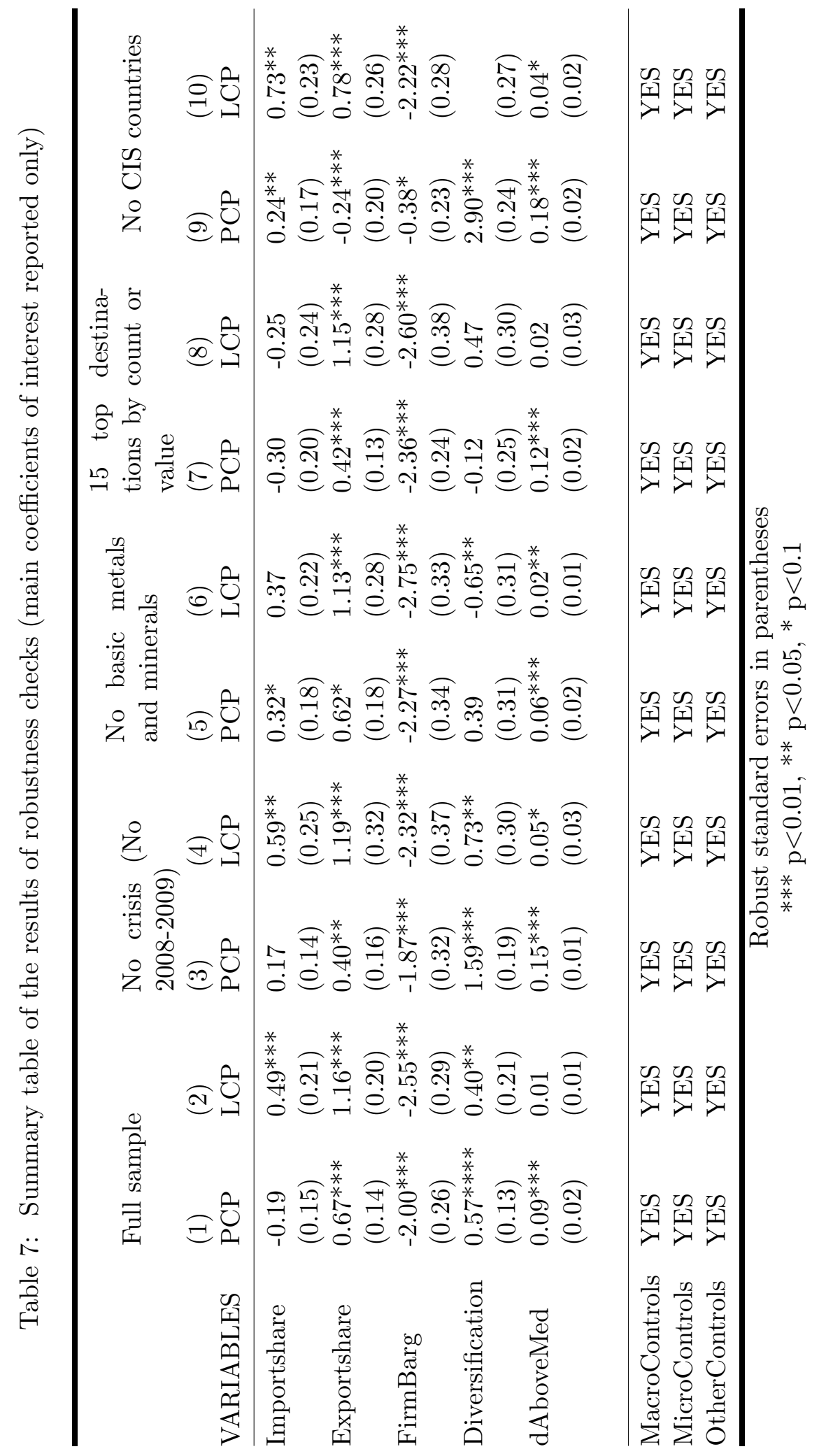


Table 8: Robustness check 1: No basic metals and minerals

\begin{tabular}{|c|c|c|c|c|c|c|}
\hline \multirow[b]{3}{*}{ VARIABLES } & \multicolumn{2}{|c|}{ Full sample } & \multicolumn{2}{|c|}{ Big exporters } & \multicolumn{2}{|c|}{ Small exporters } \\
\hline & (1) & $(2)$ & (3) & (4) & $(5)$ & (6) \\
\hline & $\mathrm{PCP}$ & $\mathrm{LCP}$ & $\mathrm{PCP}$ & LCP & $\mathrm{PCP}$ & LCP \\
\hline \multirow[t]{2}{*}{ Cust_barg } & $-0.52^{* * *}$ & $-0.34^{* *}$ & $-0.77^{* * *}$ & $-0.38^{* * *}$ & $-0.68 * * *$ & $-1.12^{* * *}$ \\
\hline & $(0.11)$ & $(0.17)$ & $(0.09)$ & $(0.19)$ & $(0.10)$ & $(0.18)$ \\
\hline \multirow[t]{2}{*}{ FirmBarg } & $-2.27^{* * *}$ & $-2.75^{* * *}$ & -0.00 & $-1.48^{* * *}$ & 0.00 & $-0.09 * * *$ \\
\hline & $(0.34)$ & $(0.33)$ & $(0.00)$ & $(0.40)$ & $(0.00)$ & $(0.03)$ \\
\hline \multirow[t]{2}{*}{ Importshare } & $0.32^{*}$ & $0.37^{*}$ & -0.00 & 0.00 & $0.45^{* * *}$ & 0.00 \\
\hline & $(0.18)$ & $(0.22)$ & $(0.00)$ & $(0.00)$ & $(0.09)$ & $(0.00)$ \\
\hline \multirow[t]{2}{*}{ Exportshare } & $0.62^{*}$ & $1.13^{* * *}$ & 0.04 & $1.07^{* * *}$ & $0.45^{*}$ & $1.04^{* * *}$ \\
\hline & $(0.18)$ & $(0.28)$ & $(0.21)$ & $(0.26)$ & $(0.42)$ & $(0.45)$ \\
\hline \multirow[t]{2}{*}{ dAboveMed } & $0.06^{* * *}$ & $0.02 * *$ & 0.02 & -0.03 & $0.15^{* * *}$ & $0.06^{*}$ \\
\hline & $(0.02)$ & $(0.01)$ & $(0.02)$ & $(0.03)$ & $(0.02)$ & $(0.02)$ \\
\hline \multirow[t]{2}{*}{ Walrascon } & $0.75^{* * *}$ & $1.35^{* * *}$ & $0.87^{* * *}$ & $1.44^{* * *}$ & $1.15^{* * *}$ & $0.59^{*}$ \\
\hline & $(0.15)$ & $(0.33)$ & $(0.15)$ & $(0.36)$ & $(0.24)$ & $(0.39)$ \\
\hline \multirow[t]{2}{*}{ Refcon } & $0.61^{* * *}$ & $1.39 * * *$ & $0.62^{* * *}$ & $1.27^{* * *}$ & $0.72^{* * *}$ & $1.01^{* *}$ \\
\hline & $(0.16)$ & $(0.33)$ & $(0.16)$ & $(0.36)$ & $(0.24)$ & $(0.45)$ \\
\hline \multirow[t]{2}{*}{ Diversification } & 0.39 & $-0.65^{* *}$ & 0.22 & -0.31 & $1.12^{* * *}$ & $-1.18^{* * *}$ \\
\hline & $(0.31)$ & $(0.31)$ & $(0.35)$ & $(0.33)$ & $(0.29)$ & $(0.39)$ \\
\hline \multirow[t]{2}{*}{ USDhedge } & $0.23^{*}$ & $0.56^{* * *}$ & 0.07 & $0.54^{* * *}$ & $0.62^{* * *}$ & $0.79^{* * *}$ \\
\hline & $(0.13)$ & $(0.21)$ & $(0.15)$ & $(0.23)$ & $(0.18)$ & $(0.21)$ \\
\hline \multirow[t]{2}{*}{ EURhedge } & 0.07 & $-0.72^{* * *}$ & $0.20^{*}$ & $-0.57 * * *$ & -0.06 & $-0.99 * * *$ \\
\hline & $(0.11)$ & $(0.22)$ & $(0.10)$ & $(0.19)$ & $(0.11)$ & $(0.26)$ \\
\hline \multirow[t]{2}{*}{ Euroarea } & 1.32 & 0.66 & $1.43^{* * *}$ & 0.47 & $2.47^{* * *}$ & $2.21^{* * *}$ \\
\hline & $(0.33)$ & $(0.43)$ & $(0.25)$ & $(0.40)$ & $(0.49)$ & $(0.54)$ \\
\hline \multirow[t]{2}{*}{ Coefvar } & $-3.69 * * *$ & $3.65^{* * *}$ & $-4.04 * * *$ & $2.60 * *$ & $-4.47 * * *$ & $-2.79^{* *}$ \\
\hline & $(0.98)$ & $(1.16)$ & $(0.74)$ & $(1.18)$ & $(0.33)$ & $(1.33)$ \\
\hline \multirow[t]{2}{*}{ Constant } & $-2.47^{* * *}$ & -0.14 & $-3.08^{* * *}$ & -0.28 & $-1.53^{* *}$ & \\
\hline & $(0.39)$ & $(0.60)$ & $(0.30)$ & $(0.59)$ & $(0.16)$ & $(0.76)$ \\
\hline Observations & $5,483,091$ & $5,483,091$ & $4,113,842$ & $4,113,842$ & $1,601,776$ & $1,601,776$ \\
\hline Time FE & YES & YES & YES & YES & YES & YES \\
\hline Region FE & YES & YES & YES & YES & YES & YES \\
\hline Industry FE & YES & YES & YES & YES & YES & YES \\
\hline Clusters & 12128 & 12128 & 11449 & 11449 & 9666 & 9666 \\
\hline
\end{tabular}

Robust standard errors in parentheses *** $\mathrm{p}<0.01,{ }^{* *} \mathrm{p}<0.05,{ }^{*} \mathrm{p}<0.1$ 
Table 9: Robustness check 2: No 2008-2009 (no Financial Crisis)

\begin{tabular}{|c|c|c|c|c|c|c|}
\hline \multirow{3}{*}{ VARIABLES } & \multicolumn{2}{|c|}{ Full sample } & \multicolumn{2}{|c|}{ Big exporters } & \multicolumn{2}{|c|}{ Small exporters } \\
\hline & (1) & $(2)$ & (3) & (4) & (5) & (6) \\
\hline & PCP & LCP & PCP & LCP & PCP & LCP \\
\hline \multirow[t]{2}{*}{ Cust_barg } & -0.027 & $-0.17^{*}$ & $-0.07^{*}$ & $-0.21^{* *}$ & -0.07 & $-0.35 * * *$ \\
\hline & $(0.04)$ & $(0.09)$ & $(0.04)$ & $(0.10)$ & $(0.06)$ & $(0.11)$ \\
\hline \multirow[t]{2}{*}{ FirmBarg } & $-1.87 * * *$ & $-2.32^{* * *}$ & $-1.93^{* * *}$ & $-2.18 * * *$ & $-1.15^{* *}$ & $-2.81^{* * *}$ \\
\hline & $(0.32)$ & $(0.37)$ & $(0.33)$ & $(0.40)$ & $(0.40)$ & $(0.61)$ \\
\hline \multirow[t]{2}{*}{ Importshare } & 0.17 & $0.59^{* *}$ & $0.69^{* * *}$ & $0.09^{* *}$ & $0.29^{* *}$ & 0.48 \\
\hline & $(0.14)$ & $(0.25)$ & $(0.12)$ & $(0.22)$ & $(0.14)$ & $(0.33)$ \\
\hline \multirow[t]{2}{*}{ Exportshare } & $0.40^{* *}$ & $1.19^{* * *}$ & $0.29^{*}$ & $1.13^{* *}$ & $0.53^{* *}$ & $1.13^{* *}$ \\
\hline & $(0.16)$ & $(0.32)$ & $(0.17)$ & $(0.33)$ & $(0.21)$ & $(0.51)$ \\
\hline \multirow[t]{2}{*}{ dAboveMed } & $0.15^{* * *}$ & $0.05^{*}$ & $0.13^{* * *}$ & 0.03 & $0.121^{* * *}$ & $0.12^{* * *}$ \\
\hline & $(0.01)$ & $(0.03)$ & $(0.01)$ & $(0.03)$ & $(0.02)$ & $(0.03)$ \\
\hline \multirow[t]{2}{*}{ Walrascon } & $0.78^{* * *}$ & $1.73^{* * *}$ & $0.36^{* *}$ & $1.50^{* *}$ & $1.95^{* * *}$ & $2.46^{* * *}$ \\
\hline & $(0.14)$ & $(0.31)$ & $(0.15)$ & $(0.39)$ & $(0.20)$ & $(0.45)$ \\
\hline \multirow[t]{2}{*}{ Refcon } & $0.41^{* * *}$ & $1.18^{* * *}$ & -0.03 & $0.68^{*}$ & $1.44^{* * *}$ & $2.30^{* * *}$ \\
\hline & $(0.14)$ & $(0.31)$ & $(0.15)$ & $(0.39)$ & $(0.22)$ & $(0.44)$ \\
\hline \multirow[t]{2}{*}{ Diversification } & $1.59^{* * *}$ & $0.73^{* *}$ & $1.52^{* * *}$ & $1.07^{* * *}$ & $2.20^{* * *}$ & 0.34 \\
\hline & $(0.19)$ & $(0.30)$ & $(0.21)$ & $(0.30)$ & $(0.33)$ & $(0.52)$ \\
\hline \multirow[t]{2}{*}{ USDhedge } & $0.19^{*}$ & $0.45^{* * *}$ & 0.06 & $0.35^{* *}$ & $0.56^{* *}$ & $0.72^{* * *}$ \\
\hline & $(0.11)$ & $(0.13)$ & $(0.10)$ & $(0.14)$ & $(0.21)$ & $(0.19)$ \\
\hline \multirow[t]{2}{*}{ EURhedge } & $0.48^{* * *}$ & $-0.39^{* *}$ & $0.49^{* *}$ & $-0.31^{* *}$ & $0.37^{* *}$ & -0.66 \\
\hline & $(0.08)$ & $(0.16)$ & $(0.07)$ & $(0.15)$ & $(0.16)$ & $(0.21)$ \\
\hline \multirow[t]{2}{*}{ Euroarea } & $0.90^{* * *}$ & $0.77^{* *}$ & 0.76 & $0.63^{*}$ & $1.67^{* * *}$ & $1.41^{*}$ \\
\hline & $(0.23)$ & $(0.37)$ & $(0.23)$ & $(0.31)$ & $(0.51)$ & $(0.80)$ \\
\hline \multirow[t]{2}{*}{ Coefvar } & $11.52^{* * *}$ & $-19.10^{* *}$ & $12.01^{* * *}$ & $-20.27^{* *}$ & $13.11^{* * *}$ & $-20.15^{*}$ \\
\hline & $(3.46)$ & $(10.21)$ & $(3.6)$ & $(10.52)$ & $(4.94)$ & (12.40) \\
\hline \multirow[t]{2}{*}{ Constant } & $-3.43^{* * *}$ & $-1.14^{* * *}$ & $-2.85^{* * *}$ & -0.85 & $-5.49 * * *$ & $-2.59^{* *}$ \\
\hline & $(0.31)$ & $(0.59)$ & $(0.31)$ & $(0.58)$ & $(0.62)$ & $(0.98)$ \\
\hline Observations & $3,682,534$ & $3,682,534$ & $2,677,821$ & $2,677,821$ & $1,004,713$ & $1,004,713$ \\
\hline Time FE & YES & YES & YES & YES & YES & YES \\
\hline Region FE & YES & YES & YES & YES & YES & YES \\
\hline Industry FE & YES & YES & YES & YES & YES & YES \\
\hline Clusters & 9242 & 9242 & 8657 & 8657 & 7056 & 7056 \\
\hline
\end{tabular}

Robust standard errors in parentheses *** $\mathrm{p}<0.01,{ }^{* *} \mathrm{p}<0.05,{ }^{*} \mathrm{p}<0.1$ 
Table 10: Robustness check 3: country-destination fixed effects for the top 15 most common destinations

\begin{tabular}{|c|c|c|c|c|c|c|}
\hline \multirow[b]{3}{*}{ VARIABLES } & \multicolumn{2}{|c|}{ Full sample } & \multicolumn{2}{|c|}{ Big exporters } & \multicolumn{2}{|c|}{ Small exporters } \\
\hline & (1) & $(2)$ & (3) & (4) & $(5)$ & (6) \\
\hline & PCP & LCP & PCP & LCP & PCP & LCP \\
\hline \multirow[t]{2}{*}{ Cust_barg } & $0.21^{* * *}$ & $0.34^{* * *}$ & 0.01 & 0.00 & $-0.11^{* *}$ & -0.06 \\
\hline & $(0.06)$ & $(0.11)$ & $(0.04)$ & $(0.08)$ & $(0.06)$ & $(0.13)$ \\
\hline \multirow[t]{2}{*}{ FirmBarg } & $-2.36^{* * *}$ & $-2.60^{* * *}$ & $-2.41^{* * *}$ & $-2.60^{* * *}$ & $-1.91^{* * *}$ & $-3.53^{* * *}$ \\
\hline & $(0.24)$ & $(0.38)$ & $(0.24)$ & $(0.25)$ & $(0.35)$ & $(0.33)$ \\
\hline \multirow[t]{2}{*}{ Importshare } & -0.30 & -0.25 & -0.24 & $0.44^{*}$ & -0.19 & $0.40^{* *}$ \\
\hline & $(0.20)$ & $(0.24)$ & $(0.20)$ & $(0.26)$ & $(0.25)$ & $(0.24)$ \\
\hline \multirow[t]{2}{*}{ Exportshare } & $0.42^{* * *}$ & $1.15^{* * *}$ & $0.36^{* * *}$ & $1.02^{* * *}$ & $0.77^{* * *}$ & $0.90 * *$ \\
\hline & $(0.13)$ & $(0.28)$ & $(0.15)$ & $(0.27)$ & $(0.19)$ & $(0.34)$ \\
\hline \multirow[t]{2}{*}{ dAboveMed } & $0.12^{* * *}$ & 0.02 & $0.07^{* * *}$ & 0.02 & $0.20 * * *$ & $0.05^{* * *}$ \\
\hline & $(0.02)$ & $(0.03)$ & $(0.03)$ & $(0.04)$ & $(0.02)$ & $(0.05)$ \\
\hline \multirow[t]{2}{*}{ Walrascon } & $0.52^{* * *}$ & $1.62^{* * *}$ & $0.32^{* *}$ & $1.36^{* * *}$ & $1.52^{* * *}$ & $2.83^{* * *}$ \\
\hline & $(0.12)$ & $(0.27)$ & $(0.14)$ & $(0.34)$ & $(0.21)$ & $(0.36)$ \\
\hline \multirow[t]{2}{*}{ Refcon } & 0.18 & $0.80^{* * *}$ & $0.06^{* *}$ & $0.80^{* * *}$ & $0.81^{* * *}$ & $2.12^{* * *}$ \\
\hline & $(0.12)$ & $(0.29)$ & $(0.03)$ & $(0.32)$ & $(0.21)$ & $(0.39)$ \\
\hline \multirow[t]{2}{*}{ divers } & -0.12 & 0.47 & -0.09 & $0.50 * * *$ & $0.53^{*}$ & 0.58 \\
\hline & $(0.25)$ & $(0.30)$ & $(0.25)$ & $(0.30)$ & $(0.30)$ & $(0.48)$ \\
\hline \multirow[t]{2}{*}{ USDhedge } & 0.04 & $0.26^{* *}$ & -0.03 & $0.29 * *$ & $0.48^{* *}$ & $0.38^{*}$ \\
\hline & $(0.11)$ & $(0.12)$ & $(0.12)$ & $(0.13)$ & $(0.19)$ & $(0.21)$ \\
\hline \multirow[t]{2}{*}{ EURhedge } & 0.12 & $-0.54^{* * *}$ & 0.09 & $-0.47^{* * *}$ & $0.10^{* *}$ & $-1.02^{* * *}$ \\
\hline & $(0.09)$ & $(0.16)$ & $(0.09)$ & $(0.16)$ & $(0.10)$ & $(0.26)$ \\
\hline \multirow[t]{2}{*}{ Euroarea } & $0.63^{* * *}$ & $12.99^{* * *}$ & $1.20^{* * *}$ & $29.18^{* * *}$ & $1.09 * * *$ & 13.81 \\
\hline & $(0.20)$ & $(0.69)$ & $(0.20)$ & $(0.68)$ & $(0.27)$ & $(0.76)$ \\
\hline \multirow[t]{2}{*}{ Coefvar } & -0.83 & 2.15 & -1.24 & 2.16 & -2.44 & $4.92^{* *}$ \\
\hline & $(1.03)$ & $(1.60)$ & $(0.91)$ & $(1.60)$ & $(0.27)$ & $(2.51)$ \\
\hline \multirow[t]{2}{*}{ Constant } & $-3.35^{* * *}$ & $-13.80^{* * *}$ & $-2.82^{* * *}$ & $-13.59^{* * *}$ & -2.44 & $-14.53^{* * *}$ \\
\hline & $(0.26)$ & $(0.80)$ & $(0.29)$ & $(0.79)$ & $(3.25)$ & $(0.91)$ \\
\hline Observations & $5,500,182$ & $5,500,182$ & $3,297,339$ & $3,297,339$ & $1,254,770$ & $1,254,770$ \\
\hline Time FE & YES & YES & YES & YES & YES & YES \\
\hline Region FE & YES & YES & YES & YES & YES & YES \\
\hline Industry FE & YES & YES & YES & YES & YES & YES \\
\hline Clusters & 14489 & 14489 & 12826 & 12826 & 10247 & 10247 \\
\hline
\end{tabular}

Robust standard errors in parentheses

*** $\mathrm{p}<0.01,{ }^{* *} \mathrm{p}<0.05,{ }^{*} \mathrm{p}<0.1$ 
Table 11: Robustness check 5: No CIS countries

\begin{tabular}{|c|c|c|c|c|c|c|}
\hline \multirow[b]{3}{*}{ VARIABLES } & \multicolumn{2}{|c|}{ Full sample } & \multicolumn{2}{|c|}{ Big exporters } & \multicolumn{2}{|c|}{ Small exporters } \\
\hline & $(1)$ & $(2)$ & $(3)$ & $(4)$ & $(5)$ & $(6)$ \\
\hline & PCP & LCP & $\mathrm{PCP}$ & LCP & PCP & $\mathrm{LCP}$ \\
\hline \multirow[t]{2}{*}{ CustBarg } & 0.012 & $0.42^{* * *}$ & $-0.16^{* * *}$ & -0.10 & -0.02 & $-0.27^{* *}$ \\
\hline & $(0.07)$ & $(0.10)$ & $(0.53)$ & $(0.07)$ & $(0.09)$ & $(0.10)$ \\
\hline \multirow[t]{2}{*}{ Firmbarg } & $-0.38^{*}$ & $-2.22^{* * *}$ & $-0.32^{*}$ & $-2.02^{* * *}$ & -0.28 & $-2.77^{* * *}$ \\
\hline & $(0.23)$ & $(0.28)$ & $(0.19)$ & $(0.32)$ & $(0.53)$ & $(0.44)$ \\
\hline \multirow[t]{2}{*}{ Importshare } & $0.24^{* *}$ & $0.73^{* * *}$ & 0.14 & $0.79 * * *$ & $0.41^{* *}$ & $0.58^{* * *}$ \\
\hline & $(0.17)$ & $(0.23)$ & $(0.16)$ & $(0.21)$ & $(0.24)$ & $(0.30)$ \\
\hline \multirow[t]{2}{*}{ Exportshare } & $-0.24^{* * *}$ & $0.78 * * *$ & $-0.53^{* * *}$ & $0.65^{* *}$ & 0.18 & $0.80 * *$ \\
\hline & $(0.20)$ & $(0.26)$ & $(0.21)$ & $(0.28)$ & $(0.26)$ & $(0.37)$ \\
\hline \multirow[t]{2}{*}{ dAboveMed } & $0.18^{* * *}$ & $0.04^{*}$ & $0.18^{* * *}$ & 0.04 & $0.20^{* * *}$ & $0.09^{* *}$ \\
\hline & $(0.02)$ & $(0.02)$ & $(0.03)$ & $(0.03)$ & $(0.02)$ & $(0.04)$ \\
\hline \multirow[t]{2}{*}{ Walrascon } & $1.12^{* * *}$ & $1.88^{* * *}$ & $0.83^{* * *}$ & $1.83^{* * *}$ & $1.91^{* * *}$ & $2.06^{* * *}$ \\
\hline & $(0.12)$ & $(0.22)$ & $(0.14)$ & $(0.28)$ & $(0.21)$ & $(0.32)$ \\
\hline \multirow[t]{2}{*}{ Refcon } & $0.48^{* * *}$ & $1.22^{* * *}$ & 0.11 & $0.91 * * *$ & $1.44^{* * *}$ & $1.95^{* * *}$ \\
\hline & $(0.13)$ & $(0.22)$ & $(014)$ & $(0.28)$ & $(0.23)$ & $(0.32)$ \\
\hline \multirow[t]{2}{*}{ Diversification } & $2.90 * * *$ & $1.31^{* * *}$ & $2.92^{* * *}$ & $1.52^{* * *}$ & $3.03^{* * *}$ & $1.07^{* *}$ \\
\hline & $(0.24)$ & $(0.27)$ & $(0.24)$ & $(0.30)$ & $(0.45)$ & $(0.45)$ \\
\hline \multirow[t]{2}{*}{ USDhedge } & 0.02 & $0.39^{* *}$ & $-0.17^{* * *}$ & 0.22 & 0.48 & $0.59^{* *}$ \\
\hline & $(0.17)$ & $(0.14)$ & $(0.13)$ & $(0.14)$ & $(0.32)$ & $(0.23)$ \\
\hline \multirow[t]{2}{*}{ EURhedge } & 0.09 & $-0.49^{* *}$ & $0.16^{* * *}$ & $-0.36^{* *}$ & 0.01 & $-0.85^{* * *}$ \\
\hline & $(0.07)$ & $(0.17)$ & $(0.07)$ & $(0.14)$ & $(0.10)$ & $(0.25)$ \\
\hline \multirow[t]{2}{*}{ Euroarea } & $1.13^{* * *}$ & $0.64^{* *}$ & $1.10^{* * *}$ & 0.51 & $1.27^{* *}$ & $1.30^{* * *}$ \\
\hline & $(0.19)$ & $(0.32)$ & $(0.18)$ & $(0.31)$ & $(0.57)$ & $(0.67)$ \\
\hline \multirow[t]{2}{*}{ Coefvar } & $-5.86^{* *}$ & $1.30 * * *$ & $-4.89^{* *}$ & 1.65 & $-13.51^{* * *}$ & -0.58 \\
\hline & $(2.90)$ & $(0.32)$ & $(1.87)$ & $(1.45)$ & $(8.56)$ & $(3.61)$ \\
\hline \multirow[t]{2}{*}{ Constant } & $-3.52^{* * *}$ & $-1.32^{* * *}$ & $-3.09^{* * *}$ & $-1.01^{* *}$ & $-4.43^{* * *}$ & $-2.24^{* * *}$ \\
\hline & $(0.32)$ & $(0.47)$ & $(0.28)$ & $(0.47)$ & $(0.70)$ & $(0.83)$ \\
\hline Observations & $3,643,788$ & $3,643,788$ & $2,422,530$ & $2,422,530$ & $1,199,910$ & $1,199,910$ \\
\hline Clusters & 11804 & 11804 & 10908 & 10908 & 7736 & 7736 \\
\hline Time FE & YES & YES & YES & YES & YES & YES \\
\hline RegionIncome FE & YES & YES & YES & YES & YES & YES \\
\hline Industry FE & YES & YES & YES & YES & YES & YES \\
\hline
\end{tabular}

Robust standard errors in parentheses

*** $\mathrm{p}<0.01,{ }^{* *} \mathrm{p}<0.05,{ }^{*} \mathrm{p}<0.1$ 
Table 12: Other Big/Small devision

\begin{tabular}{|c|c|c|c|c|}
\hline \multirow[b]{3}{*}{ VARIABLES } & \multicolumn{2}{|c|}{ Big exporters } & \multicolumn{2}{|c|}{ Small exporters } \\
\hline & (1) & $(2)$ & (3) & $(4)$ \\
\hline & $\mathrm{PCP}$ & LCP & PCP & LCP \\
\hline \multirow[t]{2}{*}{ Cust_barg } & -0.00 & -0.05 & $0.12^{*}$ & -0.11 \\
\hline & $(0.03)$ & $(0.06)$ & $(0.07)$ & $(0.13)$ \\
\hline \multirow[t]{2}{*}{ FirmBarg } & $-2.02^{* * *}$ & $-2.46^{* * *}$ & $-1.29^{* * *}$ & $-4.29 * * *$ \\
\hline & $(0.16)$ & $(0.29)$ & $(0.34)$ & $(0.79)$ \\
\hline \multirow[t]{2}{*}{ Importshare } & -0.21 & $0.51^{* * *}$ & $0.56^{* *}$ & 0.37 \\
\hline & $(0.16)$ & $(0.21)$ & $(0.22)$ & $(0.40)$ \\
\hline \multirow[t]{2}{*}{ Exportshare } & $0.64^{* * *}$ & $1.19^{* * *}$ & $0.99^{* * *}$ & 0.77 \\
\hline & $(0.15)$ & $(0.24)$ & $(0.23)$ & $(0.52)$ \\
\hline \multirow[t]{2}{*}{ dAboveMed } & $0.09^{* * *}$ & 0.01 & $0.27^{* * *}$ & $0.20^{* * *}$ \\
\hline & $(0.02)$ & $(0.01)$ & $(0.04)$ & $(0.06)$ \\
\hline \multirow[t]{2}{*}{ Walrascon } & $0.80^{* *}$ & $1.63^{* * *}$ & $1.85^{* * *}$ & $1.89^{* * *}$ \\
\hline & $(0.11)$ & $(0.22)$ & $(0.22)$ & $(0.42)$ \\
\hline \multirow[t]{2}{*}{ Refcon } & $0.44^{* * *}$ & $1.05^{* * *}$ & $1.17^{* * *}$ & $1.67^{* * *}$ \\
\hline & $(0.11)$ & $(0.23)$ & $(0.23)$ & $(0.39)$ \\
\hline \multirow[t]{2}{*}{ Diversification } & $0.55^{* * *}$ & $0.47^{* *}$ & $1.76^{* * *}$ & 0.36 \\
\hline & $(0.27)$ & $(0.28)$ & $(0.35)$ & $(0.59)$ \\
\hline \multirow[t]{2}{*}{ USDhedge } & $0.23^{* * *}$ & $0.45^{* * *}$ & $0.51^{* *}$ & $0.53^{* *}$ \\
\hline & $(0.10)$ & $(0.13)$ & $(0.19)$ & $(0.24)$ \\
\hline \multirow[t]{2}{*}{ EURhedge } & 0.09 & $-0.52^{* *}$ & 0.07 & $-0.66^{* * *}$ \\
\hline & $(0.09)$ & $(0.17)$ & $(0.17)$ & $(0.19)$ \\
\hline \multirow[t]{2}{*}{ Euroarea } & $0.83^{* * *}$ & $0.52^{* * *}$ & $1.22^{* *}$ & 0.75 \\
\hline & $(0.22)$ & $(0.17)$ & $(0.51)$ & $(0.44)$ \\
\hline \multirow[t]{2}{*}{ Coefvar } & $-3.33^{* * *}$ & $2.16^{* *}$ & $-3.05^{* *}$ & 0.11 \\
\hline & $(0.88)$ & $(1.15)$ & $(1.53)$ & $(2.84)$ \\
\hline \multirow[t]{2}{*}{ Constant } & $-2.40^{* * *}$ & -0.65 & $-4.78^{* * *}$ & $-1.50^{* *}$ \\
\hline & $(0.28)$ & $(0.48)$ & $(0.59)$ & $(0.61)$ \\
\hline Observations & $6,302,723$ & $6,302,723$ & 288,332 & 288,332 \\
\hline Time FE & YES & YES & YES & YES \\
\hline Region FE & YES & YES & YES & YES \\
\hline Clusters & 14809 & 14809 & 7730 & 7730 \\
\hline
\end{tabular}

\section{Appendix I}

\section{Data management}

For the data cleaning, when the destination country was not reported, the trading partner country (if reported) was used.

If the date when transaction is registered falls upon a weekend or holiday, the transaction is assigned to the previous working day. This is done because the exchange rate applied will be the one that was fixed for the weekend/holiday day, which is the previous business day at the Russian Foreign Exchange Market.

Transactions recorded to the destinations that are not recognized as an independent country (South Ossetia and Abkhazia) by the UN are considered being a part of the recognized country. 
Table 13: Testing the aggregate model of currency choice determinants

\begin{tabular}{|c|c|c|c|c|c|c|}
\hline \multirow[b]{3}{*}{ VARIABLES } & \multicolumn{2}{|c|}{ Full sample } & \multicolumn{2}{|c|}{ Big exporters } & \multicolumn{2}{|c|}{ Small exporters } \\
\hline & (1) & $(2)$ & (3) & (4) & (5) & (6) \\
\hline & $\mathrm{PCP}$ & LCP & PCP & LCP & PCP & $\mathrm{LCP}$ \\
\hline Walrascon & $\begin{array}{l}1.34^{* * *} \\
(0.11)\end{array}$ & $\begin{array}{l}2.48^{* * *} \\
(0.19)\end{array}$ & $\begin{array}{l}1.17^{* * *} \\
(0.12)\end{array}$ & $\begin{array}{l}2.21^{* * *} \\
(0.23)\end{array}$ & $\begin{array}{l}2.00^{* * *} \\
(0.16)\end{array}$ & $\begin{array}{l}3.24^{* * *} \\
(0.19)\end{array}$ \\
\hline Refcon & $\begin{array}{l}0.32^{* * *} \\
(0.11)\end{array}$ & $\begin{array}{l}2.09^{* * *} \\
(0.18)\end{array}$ & $\begin{array}{l}0.12 \\
(0.12)\end{array}$ & $\begin{array}{l}1.93^{* * *} \\
(0.21)\end{array}$ & $\begin{array}{l}1.15^{* * *} \\
(0.16)\end{array}$ & $\begin{array}{l}2.83^{* * *} \\
(0.25)\end{array}$ \\
\hline Cust_barg_ag & $\begin{array}{l}-0.69^{* * *} \\
(0.13)\end{array}$ & $\begin{array}{l}-1.62^{* * * *} \\
(0.25)\end{array}$ & $\begin{array}{l}-0.77^{* * *} \\
(0.14)\end{array}$ & $\begin{array}{l}-1.15^{* * * *} \\
(0.24)\end{array}$ & $\begin{array}{l}-0.04 \\
(0.22)\end{array}$ & $\begin{array}{l}-3.22^{* * * *} \\
(0.54)\end{array}$ \\
\hline Importshare & $\begin{array}{l}0.27^{* *} \\
(0.12)\end{array}$ & $\begin{array}{l}0.77^{* * *} \\
(0.20)\end{array}$ & $\begin{array}{l}0.23 \\
(0.15)\end{array}$ & $\begin{array}{l}0.58^{* * *} \\
(0.20)\end{array}$ & $\begin{array}{l}0.25^{*} \\
(0.14)\end{array}$ & $\begin{array}{l}0.66^{* *} \\
(0.26)\end{array}$ \\
\hline USDhedge & $\begin{array}{l}0.20^{* * *} \\
(0.0645)\end{array}$ & $\begin{array}{l}0.20^{* *} \\
(0.10)\end{array}$ & $\begin{array}{l}0.21^{* * *} \\
(0.07)\end{array}$ & $\begin{array}{l}0.25^{* * *} \\
(0.09)\end{array}$ & $\begin{array}{l}0.17^{* *} \\
(0.08)\end{array}$ & $\begin{array}{l}0.09 \\
(0.17)\end{array}$ \\
\hline EURhedge & $\begin{array}{l}0.18^{* *} \\
(0.08)\end{array}$ & $\begin{array}{l}0.15^{* *} \\
(0.07)\end{array}$ & $\begin{array}{l}0.16^{*} \\
(0.09)\end{array}$ & $\begin{array}{l}0.12^{*} \\
(0.06)\end{array}$ & $\begin{array}{l}0.36^{* * *} \\
(0.11)\end{array}$ & $\begin{array}{l}0.36^{* * *} \\
(0.14)\end{array}$ \\
\hline Euroarea & $\begin{array}{l}-0.18^{* *} \\
(0.09)\end{array}$ & $\begin{array}{l}3.93^{* * *} \\
(0.14)\end{array}$ & $\begin{array}{l}-0.30^{* * *} \\
(0.08)\end{array}$ & $\begin{array}{l}3.72^{* * *} \\
(0.15)\end{array}$ & $\begin{array}{l}0.36^{* * *} \\
(0.13)\end{array}$ & $\begin{array}{l}4.69^{* * *} \\
(0.19)\end{array}$ \\
\hline Coefvar & $\begin{array}{l}-2.70^{* * *} \\
(0.26)\end{array}$ & $\begin{array}{l}-0.76^{* *} \\
(0.31)\end{array}$ & $\begin{array}{l}-2.90^{* * *} \\
(0.27)\end{array}$ & $\begin{array}{l}-0.88^{* *} \\
(0.41)\end{array}$ & $\begin{array}{l}-2.34^{* * *} \\
(0.46)\end{array}$ & $\begin{array}{l}-0.37 \\
(0.42)\end{array}$ \\
\hline Constant & $\begin{array}{l}-1.47^{* * *} \\
(0.13)\end{array}$ & $\begin{array}{l}-6.61^{* * *} \\
(0.29)\end{array}$ & $\begin{array}{l}-1.40^{* * *} \\
(0.14)\end{array}$ & $\begin{array}{l}-6.41^{* * *} \\
(0.33)\end{array}$ & $\begin{array}{l}-1.66^{* * *} \\
(0.22)\end{array}$ & $\begin{array}{l}-7.03^{* * *} \\
(0.31)\end{array}$ \\
\hline Observations & $8,614,721$ & $8,614,721$ & $6,467,539$ & $6,467,539$ & $2,147,182$ & $2,147,182$ \\
\hline Time FE & YES & YES & YES & YES & YES & YES \\
\hline Region FE & YES & YES & YES & YES & YES & YES \\
\hline Industry FE & YES & YES & YES & YES & YES & YES \\
\hline Clusters & 20992 & 20992 & 19618 & 19618 & 16786 & 16786 \\
\hline
\end{tabular}

Product-destinations with less than 3 transactions per all firms exporting there were omitted in order to escape the singularity of the variation matrix. Destinations with less than two firms are omitted in the process of construction of the Diversification measure. The construction of Diversification measure and additional data trancation is explained below.

\section{Hedging variable construction}

Along the lines of Goldberg \& Tille (2008b) and Goldberg \& Tille (2008b), the hedging variable is built in order to catch the exchange rate hedging opportunity. It therefore reflects the covariances between marginal costs and exchange rate $\rho\left(m_{e d}, s_{e d}\right)$ and $\rho\left(m_{e v}, s_{e v}\right)$. We assume that the measure is different for different industries. Producer marginal costs are modelled as $m_{e d}^{i n d}=w_{e}^{\text {ind }}+\frac{(1-\alpha)}{\alpha} * c_{d}$, where $w_{e}^{\text {ind }}$ is the wage index per industry representing the unit marginal cost of the exporter, and $c_{d}$ is the sensitivity of the marginal costs to the changes of the demand in the destination country. We proxy for the marginal costs by constructing a monthly values for $m_{e d}^{i n d}$. 
Table 14: Testing the firm level currency choice determinants

\begin{tabular}{|c|c|c|c|c|c|c|c|}
\hline \multirow[b]{3}{*}{ VARIABLES } & \multicolumn{2}{|c|}{ Full sample } & \multicolumn{3}{|c|}{ Big exporters } & \multicolumn{2}{|c|}{ Small exporters } \\
\hline & \multirow{2}{*}{$\begin{array}{l}(1) \\
\mathrm{PCP}\end{array}$} & \multirow{2}{*}{$\begin{array}{l}(2) \\
\mathrm{LCP}\end{array}$} & & \multirow{2}{*}{$\begin{array}{l}(4) \\
\text { LCP }\end{array}$} & \multirow{2}{*}{$\begin{array}{l}(5) \\
\mathrm{PCP}\end{array}$} & \multirow{2}{*}{$\begin{array}{l}(6) \\
\mathrm{LCP}\end{array}$} \\
\hline & & & PCP & & & & \\
\hline \multirow[t]{2}{*}{ Cust_barg } & $0.45^{* * *}$ & $-0.30 * * *$ & \multirow{2}{*}{\multicolumn{2}{|c|}{$\begin{array}{l}0.36^{* * *} \\
(0.05)\end{array}$}} & $-0.40^{* * *}$ & $0.61^{* * *}$ & -0.13 \\
\hline & $(0.05)$ & $(0.08)$ & & & $(0.13)$ & $(0.07)$ & $(0.13$ \\
\hline \multirow[t]{2}{*}{ FirmBarg } & $-0.95^{* * *}$ & $-1.22^{* * *}$ & \multirow{2}{*}{\multicolumn{2}{|c|}{$\begin{array}{l}-1.07^{* * *} \\
(0.14)\end{array}$}} & $-1.10^{* * *}$ & 0.13 & $-1.26^{\circ}$ \\
\hline & $(0.13)$ & $(0.25)$ & & & $(0.27)$ & $(0.18)$ & $(0.47$ \\
\hline \multirow[t]{2}{*}{ dAboveMed } & $0.07^{* * *}$ & $0.09^{* * *}$ & \multirow{2}{*}{\multicolumn{2}{|c|}{$\begin{array}{l}0.06^{* * *} \\
(0.00)\end{array}$}} & $0.08^{* * *}$ & $0.12^{* * *}$ & $0.13^{*}$ \\
\hline & $(0.01)$ & $(0.01)$ & & & $(0.01)$ & $(0.02)$ & (0.02 \\
\hline \multirow[t]{2}{*}{ Walrascon } & $0.28^{*}$ & $0.88^{* * *}$ & \multirow{2}{*}{\multicolumn{2}{|c|}{$\begin{array}{l}0.10 \\
(0.18)\end{array}$}} & $0.75^{* * *}$ & $0.86^{* * *}$ & $1.44^{*}$ \\
\hline & $(0.16)$ & $(0.17)$ & & & $(0.24)$ & $(0.17)$ & $(0.26$ \\
\hline \multirow[t]{2}{*}{ Refcon } & -0.08 & $0.90 * * *$ & \multirow{2}{*}{\multicolumn{2}{|c|}{$\begin{array}{l}-0.26 \\
(0.17)\end{array}$}} & $0.73^{* * *}$ & $0.59 * * *$ & $1.72^{*}$ \\
\hline & $(0.16)$ & $(0.17)$ & & & $(0.23)$ & $(0.18)$ & $(0.23$ \\
\hline \multirow[t]{2}{*}{ Diversification } & $1.47^{* * *}$ & $0.44^{*}$ & \multirow{2}{*}{\multicolumn{2}{|c|}{$\begin{array}{l}1.53^{* * *} \\
(0.14)\end{array}$}} & 0.43 & $1.30 * * *$ & $1.01^{*}$ \\
\hline & $(0.12)$ & $(0.24)$ & & & $(0.27)$ & $(0.17)$ & $(0.34$ \\
\hline \multirow[t]{2}{*}{ USDhedge } & 0.06 & $0.19^{* *}$ & \multirow{2}{*}{\multicolumn{2}{|c|}{$\begin{array}{l}0.05 \\
(0.05)\end{array}$}} & $0.22^{* * *}$ & $0.14^{*}$ & 0.12 \\
\hline & $(0.04)$ & $(0.08)$ & & & $(0.08)$ & $(0.08)$ & $(0.15$ \\
\hline EURhedge & $0.19^{* * *}$ & $0.17^{* * *}$ & $0.19^{*}$ & & 0.10 & $0.30^{* * *}$ & $0.39^{*}$ \\
\hline & $(0.05)$ & $(0.06)$ & $(0.06$ & & $(0.06)$ & $(0.09)$ & $(0.12$ \\
\hline Dollarpeg & $1.97^{* * *}$ & $4.84^{* * *}$ & $2.19^{*}$ & & $4.93^{* * *}$ & $1.71^{* * *}$ & $6.00^{*}$ \\
\hline & $(0.23)$ & $(0.26)$ & $(0.26$ & & $(0.28)$ & $(0.48)$ & $(0.60$ \\
\hline Euroarea & $-0.33^{* * *}$ & $2.21^{* * *}$ & -0.23 & & $2.28^{* * *}$ & $-0.37^{* *}$ & $2.12^{*}$ \\
\hline & $(0.09)$ & $(0.16)$ & $(0.09$ & & $(0.19)$ & $(0.15)$ & $(0.23$ \\
\hline Coefvar & $-1.04^{* * *}$ & -0.11 & -1.26 & $k * *$ & -0.51 & $-0.58^{*}$ & 0.65 \\
\hline & $(0.20)$ & $(0.33)$ & $(0.19$ & & $(0.48)$ & $(0.33)$ & $(0.53$ \\
\hline Constant & $-2.49 * * *$ & $-5.52 * * *$ & -2.35 & & $-5.36^{* * *}$ & $-2.97 * * *$ & $-6.37^{3}$ \\
\hline & $(0.18)$ & $(0.25)$ & $(0.19$ & & $(0.31)$ & $(0.22)$ & $(0.34$ \\
\hline Observations & $7,727,208$ & $7,727,208$ & 5,725 &, 362 & $5,725,362$ & $2,001,846$ & 2,001 \\
\hline Time FE & YES & YES & YES & & YES & YES & YES \\
\hline Region FE & YES & YES & YES & & YES & YES & YES \\
\hline Clusters & 18123 & 18123 & 1693 & & 16937 & 14319 & 14319 \\
\hline & & $\begin{array}{l}\text { st standa } \\
* \mathrm{p}<0.01\end{array}$ & erro & Ci: & $\begin{array}{c}\text { arentheses } \\
\mathrm{p}<0.1\end{array}$ & & \\
\hline & Table & 5: $\mathrm{AIC}$ sco & tes & salit & ples/specific & cations & \\
\hline & & Full Sa & mple & Big & Exporters & Small Expo & rters \\
\hline Model & & $\mathrm{AIC} \mathrm{scc}$ & & AIC & score & AIC score & \\
\hline Main & & 691234 & & 5377 & 585 & 1458738 & \\
\hline Only Aggregate & & & & & & & \\
\hline Only Firm-level & & & & & & & \\
\hline Alternative Cus & tBarg & & & & & & \\
\hline No basic metals & and miner & & & 4573 & 348 & 1443800 & \\
\hline No crisis & & 405107 & & 3036 & 031 & 970060 & \\
\hline Top 15 by coun & or value & 491504 & & & & & \\
\hline No CIS countrie & & 3496660 & & 2401 & 222 & 1028017 & \\
\hline
\end{tabular}


Table 16: BIC scores for samples/specifications

Full Sample Big Exporters Small Exporters

\begin{tabular}{llll}
\hline Model & BIC score & BIC score & BIC score \\
Main & 6913273 & 5378498 & 1459576
\end{tabular}

Only Aggregate

Only Firm-level

Alternative CustBarg

No basic metals and minerals

No crisis

$\begin{array}{lll} & 4574194 & 1444587 \\ 4051199 & 3036851 & 970817 \\ 4916095 & & \\ 3497551 & 2402086 & 1028017\end{array}$

Top 15 by count or value

No CIS countries

3497551

Note: AIC and BIC scores are not comparable across different sample

sizes. The solid lines separate samples of the same size.

The $w_{e}$ values are provided monthly for the aggregated industries by the Rosstat ${ }^{27}$. Following GT we set $\alpha$ at $0.65 . c_{d}$ is the log of real consumption in the destination countries. The real consumption values are acquired from the IFS database for the quarters. For some of the destinations we had to use the yearly values, therefore the estimation procedure was also adjusted (see below for clarifications). $s_{e i}$ represents the exchange rate movement of currency $i$ in units of the domestic currency (roubles). The increase in $s_{e i}$ will represent the depreciation of the roubles.

The OLS ${ }^{28}$ specification that is used to determine the hedging opportunities is:

$$
m_{e d, t}^{i n d}=\gamma_{0}+\gamma_{1} s_{e U S D, t}+\gamma_{1} * s_{e E U R, t}
$$

The regression coefficients $\gamma_{1}$ and $\gamma_{2}$ correspond to estimates of covariences $\rho\left(m_{e v}, s_{e U S D}\right)$ and $\rho\left(m_{e v}, s_{e U S D}\right)$ accordingly, for the given period. $0<\gamma_{1}<\gamma_{2}$ represents the situation when USD provides a statistically significant hedging opportunity. $0<\gamma_{2}<\gamma_{1}$ corresponds to the analogous situation for the EUR. If none of the coefficients is higher than 0 , the hedging dummies take value of 0 for both of the currencies.

Therefore, we are able to construct a per-industry per-destination measure of covariance movements between the marginal costs and exchange rates, which brings us to more precision for the estimation of the hedging motive. We improve the GT measure by breaking it down to industries.

\section{Real consumption data}

As for some of the destinations the real consumption was not available for the quarterly periods, we construct the variable for the yearly basis, following a 4-year rolling regression window. These destinations sum up to roughly $13 \%$ of total trade flows in the population sample. It is not expected to introduce big bias to the according indicators. Slight downwards bias might be expected as the yearly real consumption represents lower variation than the quarterly one.

\section{Coefficient of exchange rate variation}

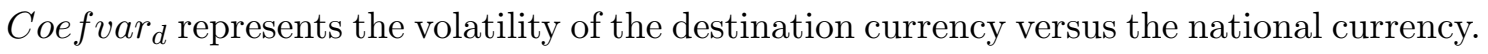
The higher is the volatility at the destination, the more likely the exporter to use PCP or VCP. The measure is calculated through the variation coefficient in order to dispose the level effects. It is constructed as a rolling coefficient for quarters based on the previous

\footnotetext{
${ }^{27}$ The Russian Bureau of Statistical Survey

${ }^{28}$ Robust standard errors, rolling window of 4 quarters as in GT.
} 
four quarters over the daily reported values 29 , As a robustness check we also perform a rolling coefficient over a 2-year window. The higher is the value, the more likely the exporter to price in PCP or VCP.

\section{Bargaining power}

When calculating bargaining power of the seller (transaction to all imports at the destination of the product) about $10 \%$ of the transactions could not be matched on the HS6 level with the data provided by COMTRADE. The issue arose because of reporting the exports into the "other" category or the lack of precision in the reports to international bureaus. We consider our core dataset being the true data, as these are the reports to Customs. For the transactions that can not be matched to the COMTRADE-HS6 directly, I use an aggregative HS4 statistics. We estimate the bargaining power for these transactions with the following procedure:

As some HS6 categories are not reported to be imported from Russia at the destination with COMTRADE, but appear to be in the data and being exported, we correct the sample on the firm shares we use the following procedure:

- share of Russian imports at the destination:

$$
\text { Seller_barg_ag } g_{d t}=\frac{\text { totsales }^{t, d}}{\text { tot_RUSimport_HS } 4_{\text {comtrade }}^{t, d}} * \text { ShareHS } 6^{t, d}
$$

- share of firm sales at the destination:

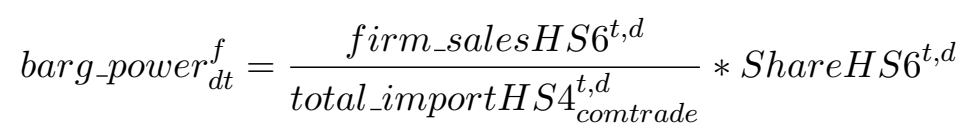

- share of transaction at the destination:

$$
\text { Seller_barg }=\frac{\text { transaction value }}{\text { total_RUSimport_HS } 4_{\text {comtrade }}} * \text { Share HS } 6^{t, d}
$$

, where ShareHS $6^{t, d}=\frac{\text { total_import } H S 6_{\text {comtrade }}^{t, d}}{\text { total_import } H S 4_{\text {comtrade }}^{t, d}}$ represent the total share of imports of HS6 product in HS4 category at the destination within the year.

HS4 corresponds to the according group of HS6-products where the "unmatched" transaction is placed. Therefore, the first term in all the equation represents the share of the transaction in the "mismatch" of the HS4 category, and the second - the share of HS6 exports to the destination in all HS4 exports to the destination. Only "unmatched" transactions for which the constraint $0<$ bargpower $_{p d t}^{t r}<1$ were left in the sample. This correction can generate downwards bias for the measure, but the result should hold.

This allows procedure allows us to correct for the data mismatch through calculating the approximate bargaining power, utilizing the importing pattern of the exporting partner.

\section{Diversification index constraint}

As mentioned in the main text, diversification index is constructed in the following manner: Diversification $_{h s 4, d,-f}=1-H H_{h s 4, d,-f}$ and Diversification ${ }_{h s 4, d,-f} \in[0 ; 0.67]$. On the examples we can illustrate how different Diversification indexes are obtained:

\footnotetext{
${ }^{29}$ The daily reports on the exchange rates are taken from the Central Bank of Russia, therefore they capture the face-off dynamics of the rates for the firms
} 
Tables A.1-1 to A.1-4: Different Diversification scenarios

\begin{tabular}{|c|c|c|}
\hline \multicolumn{3}{|c|}{ Scenario 1: complete diversification } \\
\hline $\mathrm{CC}$ & share & \multirow{4}{*}{$\begin{array}{l}\text { Diversification index } \\
0.67\end{array}$} \\
\hline $\mathrm{VCP}$ & 0.33 & \\
\hline $\mathrm{PCP}$ & 0.33 & \\
\hline LCP & 0.33 & \\
\hline
\end{tabular}

\begin{tabular}{|l|c|l|}
\hline \multicolumn{3}{|c|}{ Scenario 2: Extreme Pricing 1 } \\
\hline CC & share & \multirow{2}{*}{ Diversification index } \\
VCP & 1 & \multirow{2}{*}{0.0} \\
\hline PCP & 0 & \\
\hline LCP & 0 & \\
\hline
\end{tabular}

\begin{tabular}{|l|c|l|}
\hline \multicolumn{3}{|c|}{ Scenario 3: Extreme Pricing 2 } \\
\hline CC & share & \multirow{2}{*}{ Diversification index } \\
VCP & 0 & \multirow{2}{*}{0.0} \\
PCP & 1 & 0.0 \\
\hline LCP & 0 & \\
\hline
\end{tabular}

\begin{tabular}{|c|c|c|}
\hline \multicolumn{3}{|c|}{ Scenario 4: Diversified pricing } \\
\hline $\mathrm{CC}$ & share & \multirow{4}{*}{$\begin{array}{l}\text { Diversification index } \\
0.34\end{array}$} \\
\hline VCP & 0.8 & \\
\hline PCP & 0.1 & \\
\hline LCP & 0.1 & \\
\hline
\end{tabular}

Scenarios 2 and 3 indicate that statistically, the diversification index of 0 will mean that all other competitors price in the same way, as this measure does not differentiate between the choices. This implies that it will not show difference if the others are pricing completely in VCP or in LCP or PCP. As the main finding on "coalescing" effect in the literature is concerned with the fact that communion in pricing choices of competitors is observed on the homogeneous goods markets, I am interested in the case of Diversification ${ }_{h s 4, d,-f}=0$ being attributed to the case when $H H_{h s 4, d,-f}=1_{v}^{2}$, or in other words, the competitors price only in VCP. If this condition is fulfilled, then the increase in Diversification measure will be associated with the increase of probability of pricing in either PCP or LCP. Then the coefficients will report the increase (or fall) in log-likeliness or odd ratios of pricing in other then $V C P$ when your competitors at the destination are doing the diversified portfolio. The graph below indicates the "zero" cases.

As seen from the graph, the majority of the "zeros" indeed contribute to the VCPdomination, but we observe certain LCP- and PCP-"zero" cases. These cases constitute to less then $5 \%$ of the product-destination diversification index calculations, constituting to less then $3 \%$ of the trade volumes. Looking at close into the cases of "bad" zeros, I find that in $80 \%$ of the cases both for LCP-concerned and PCP-concerned cases the firm at interest did the same pricing. This means that the firm for which the diversification index is calculated replicated the decision of it's competitor to price completely in LCP and PCP with 0.8 probability.

Upon further investigation, I find that $66 \%$ of the cases the firms in the PCP-concerned cases have exported only once to that destination. This supports the fact that first-time exporting to the destination of where there are no firms of your origin doing PCP is a risky behavior, as it increases the exposure to not only the specific market frictions, but also to the excessive exposure to the exchange rate fluctuations compared to other competitors at the destination.

The alike situation is observed for the LCP. $60 \%$ of the firms in the LCP-concerned "zero"-cases have exported only once to that destinations.

I omit the cases of "bad" zeros from the sample, so that the diversification index has the meaning of "diversifying from PCP" when it goes from 0 . The reported results therefore explain how likely I am to apply LCP compared to VCP or PCP compared to VCP when my home competitors at the destination start using not only VCP at the destination.

\section{Manski reflection problem}

In our framework Manski reflection problem that I do not know if an exporter does $k$ choice because everybody else is doing $k$ choice, or everybody else is doing $k$ choice because they 
observe the given exporter doing $k$ choice. This has been a big debate in the literature that is concerned with agent-behavior. I cannot assume the independent decision-making as this is the core of the coalescing determinant, and therefore I do not claim any causal directions with this measure, as we are simply aiming to exploit the existent data.

\section{Types of value calculation}

The export by the Russian Federation are reported to the Customs Office as FOB (free on board), when the imports reported to COMTRADE are CIF (cost, insurance and freight). Therefore, different accounting is used for the same flow.

In order to solve this problem, we use COMTRADE-based database BACI, which corrects for the transport costs in reported imports and reports FOB imports. I skip the description of the construction of the BACI dataset, as it can be found in great detail in other sources, such as, for example, Gaulier \& Zignano (2010). It should be noted that BACI has been missing about 1,3 million transactions at the imported destination - as the destinations did not report to be importing at HS6 level products from Russian Federation. With the procedure reported above I were able to correct for the majority of the mismatch (about 90\%) and for the rest of them I used the raw COMTRADE reported imports. Even though it might be a source of a downward bias, we do not consider it being any sort of significant distortion to our findings.

\section{Source of the exchange rates}

If the CBR does not trade the currency and does not report the exchange rate for the country's currency, we set the coefficient of variation equal to 1 . This is plausible as the fact that the exporters cannot freely exchange the currency emphasizes the fact that they cannot forecast or determine their profits and therefore will use the PCP or VCP.

For the case of Serbia and Montenegro that got separated in 2006 in two separate countries, I use volatility of the Serbian dinar as it is believed to most fully depict the fluctuations of the exchange rate. As the level and the real value of the exchange rate does not matter for the calculations, this should not generate any bias.

\section{Econometric notice}

I perform the general tests for MNLM. The tests reported are on the full-sample modified test. Upon request other tests can be reported. After providing the results of the test, I discuss the eligibility of usage of MNLM for specification.

Full multinomial logit specification with variables therefore is:

The aggregated test is specified as:

$$
\begin{aligned}
& \log \left(\frac{p_{i j}}{p_{i 0}}\right)=\beta_{0 j}+\beta_{1 j} * \text { EURhedge }_{i, d}+\beta_{2 j} * \text { USDhedge }_{i, d}+\beta_{3 j} * \text { Coefvar }_{d}+ \\
&+\beta_{4 j} * \text { Euroarea }_{d}+ \beta_{5 j} * \text { Dollarpeg }_{d}+\beta_{6 j} * \text { Walrascon }_{i}+\beta_{7 j} * \text { Ref }_{\text {con }}+ \\
&+\beta_{8 j} * \text { Cust_barg_ag } \\
& i r, d, t
\end{aligned}
$$

The firm-level test has a form of:

$$
\begin{aligned}
& \log \left(\frac{p_{i j}}{p_{i 0}}\right)=\beta_{0 j}+\beta_{1 j} * \text { EURhedge }_{i, d}+\beta_{2 j} * \text { USDhedge }_{i, d}+\beta_{3 j} * \text { Coefvar }_{d}+ \\
& +\beta_{4 j} * \text { Euroarea }_{d}+\beta_{5 j} * \text { Dollarpeg }_{d}+\beta_{6 j} * \text { Walrascon }_{i}+\beta_{7 j} * \text { Ref }_{\text {con }_{i}}+\beta_{6 j} * \text { Diversification }_{i,-f, d}+ \\
& \quad+\beta_{6 j} * \text { Cust_barg tr } \\
& \quad \text { tr }
\end{aligned}
$$


Time subscript is neglected for brevity. All regressions are run with the industry and year clustered robust standard errors on time (year) and industry (HS6 level). Changing clusters to HS4-year does not change the results, so we prefer to stay at the more disaggregated level of HS6. Time dimension of clusters is taken at the year level, with time fixed effects entering the regression on the yearly level too. The level of aggregation provides us with sufficient number of clusters, which increase the estimation precision. Reduction of time-aggregation of clusters to a month does not provide sufficient changes to the results, but incommensurably increases the process of estimation.

\section{Wald test for independent variables}

I compute Wald tests for all specifications, as even though the LR test is believed to be superior in power, on the big dataset and more complex models, the computational costs of the test become far too great.

The Wald tests is performed in the following way: Let bet $a_{k}$ be the vector of J-1 coefficients associated with the certain (or set of certain) independent variable(s). Then $\hat{\operatorname{Var}}\left(\hat{\beta}_{k}\right)$ is the estimated covariance matrix. If the null hypothesis of all the coefficients associated with the certain independent variable is true, the Wald statistic $W_{k}=\hat{\beta}_{k}^{\prime} \operatorname{Var}\left(\hat{\beta}_{k}\right)^{-1} \hat{\beta}_{k}$ will chi-square distributed statistic with J-1 degrees of freedom.

Table A1.1: Wald independent variables test results

Ho: All coefficients associated with given variable(s) are 0

\begin{tabular}{llll}
\hline Variable & Chi2 & df & P>chi2 \\
\hline cust_barg1 & 101.696 & 2 & 0.000 \\
seller_barg & 73.373 & 2 & 0.000 \\
Walrascon & 30.175 & 2 & 0.000 \\
Refcon & 29.972 & 2 & 0.000 \\
Diversification & 147.126 & 2 & 0.000 \\
usd_hedge & 405.246 & 2 & 0.091 \\
eur_hedge & 1760.696 & 2 & 0.000 \\
Dollarpeg & 398.376 & 2 & 0.000 \\
Euroarea & 187.685 & 2 & 0.000 \\
Coefvar2 & 29.394 & 2 & 0.000 \\
\hline
\end{tabular}

From the results of the test I can reject the hypothesis that the variables do not effect the choices of currency pricing (For all variables except for usd_hedge at $99 \%$ level).

\section{The Wald tests for combining the alternatives $(\mathrm{N}=7757542)$}

The results of the test show that none of the dependent categories can be combined.

\section{Small-Hsiao tests of IIA assumption $(\mathrm{N}=7757542)$}

Small-Hsiao test divides the sample into two subsamples and estimates weighted average of the coefficients of the unrestricted multinomial logit in the following manner:

$$
\hat{\beta}_{u}^{S_{1}, S_{2}}=\left(\frac{1}{\sqrt{2}} \hat{\beta}_{u}^{S_{1}}\right)+\left[1-\frac{1}{\sqrt{2}}\right] \hat{\beta}_{u}^{S_{2}}
$$


Table A1.2: Wald alternatives combinations test result

Ho: All coefficients except intercepts associated with a given pair of alternatives are 0 (i.e., alternatives can be combined)

\begin{tabular}{llll} 
Alternatives tested & Chi2 & df & P $>$ chi2 \\
\hline $0-1$ & 99068.884 & 23 & 0.000 \\
$0-2$ & 13961.060 & 23 & 0.000 \\
$1-2$ & 41881.089 & 23 & 0.000 \\
\hline
\end{tabular}

The restricted sample is constructed from the second subsample by elimating all cases of one of the alternatives. The Small-Hsiao statistic is constructed as

$$
S H=-2\left[L\left(\hat{\beta}_{u}^{S_{1}, S_{2}}\right)-L\left(\hat{\beta}_{r}^{S_{2}}\right)\right]
$$

The $\mathrm{SH}$ statistic is chi-square distributed with $\mathrm{k}+1$ degrees of freedom ( $\mathrm{k}$ being the number of independent variables).

Table A1.3: Small-Hsiao test results

Ho: All coefficients except intercepts associated with a given pair of alternatives are 0 (i.e., alternatives can be combined)

\begin{tabular}{lllllll} 
Omitted & $\operatorname{lnL}($ full) & $\operatorname{lnL}($ omit $)$ & Chi2 & df & P $>$ chi2 & evidence \\
\hline 0 & -329000 & -328000 & 2354.675 & 24 & 0.000 & against Ho \\
0 & -1240000 & -1240000 & 315.482 & 24 & 0.000 & against Ho \\
\hline
\end{tabular}

The Small-Hsiao test indicate that IIA assumption is violated. It should be noted that Hausman test cannot be performed here due to robust SE and clustering.

\section{General relevance of the MNLM}

The IIA assumption is not satisfied - which is a common critique against using the MNLM, as IIA implies that MNLM should be used when the outcome categories "can be plausibly assumed to be distinct and weighted independently in the eyes of each decision maker" Hausman \& McFadden (1984) or the alternatives should be "dissimilar" Amemiya (1981).

Conventionally, it indicates that I need to estimate the MNPM (multinomial probit model). As the according estimation does not converge, I admit that I cannot technically do better then MNLM, but I also draw attention to the widespread critique of the eligibility of IIA tests among statisticians. It should be noted first that both the Hausman test and Small-Hsiao test are based on the restricted choic ${ }^{30}$ tests.

The first and the main strand of critique I cite is connected to the simulation studies performed by (Fry \& Harris, 1998) (Fry \& Harris, 1996) and Cheng \& Long (2006) that indicate that even on the very large datasets the simulated probability of rejecting Ho was quite different then the nominal level. They also note that the performance of the tests varies significantly between different data structures. (Cheng \& Long, 2006) state "tests of IIA assumption that are based on the estimation of a restricted choice set are unsatisfactory for applied work".

\footnotetext{
${ }^{30}$ implies that to test IIA for each alternative it deletes observations with that alternative and re-estimates the the model considering only the alternatives that are left, and then compares the test statistic of the original and new models
} 
Another strand of argument is concerned with the comparison between the multinomial logit model and binary logits in the Small-Hsiao test. As Small-Hsiao test splits the sample randomly, two issues arise: the number and size of clusters in each sub-sample and the multitude of different random splits. To be more precise, there could exist a number of SH statistic that will actually show that IIA is satisfied.

All in all, I can conclude, that even though I admit potential absence of robustness in the econometric specification, I can not yet perform better then multinomial logit model. Therefore, the achieved results are just as good as they can be, and should be considered for further inference and discussions in the area, before a better estimation technics become more feasible. 